\title{
Pluralismo cultural y la cuestión animal: tres casos de conflicto
}

\author{
Daniel Romero Campoy \\ Universidad Carlos III de Madrid, España
}

Cita recomendada. ROMERO CAMPOY, D., Pluralismo cultural y la cuestión animal: tres casos de conflicto, dA. Derecho Animal (Forum of Animal Law Studies) 12/2 (2021). - DOI https://doi.org/10.5565/rev/da.560

\section{Resumen}

El presente estudio aborda tres casos conflictivos entre la consideración moral de los animales y el pluralismo cultural: la tauromaquia, la carne kosher y halal y la autonomía de los pueblos indígenas. Para ello, se muestran tres enfoques diferentes: antropocentrismo fuerte, antropocentrismo débil (bienestarismo) y biocentrismo débil (una teoría de los derechos de los animales). El objetivo es ofrecer argumentos de las diferentes propuestas y reflexionar sobre ellas, estableciendo una serie de conclusiones.

Palabras clave: animales; derechos; pluralismo; cultura; religión; tauromaquia; indígenas; kosher; halal.

Abstract - Cultural pluralism and the animal question: three cases of conflict

This study tackles three cases conflicted between the moral consideration of non-human animals and cultural pluralism: bullfighting, kosher and halal meat and the autonomy of indigenous peoples. To do so, three different approaches are shown: strong anthropocentrism, weak anthropocentrism (animal welfare) and weak biocentrism (a theory of animal rights). The aim is to provide arguments in order to reflect upon the different proposals, establishing a series of conclusions.

Key words: animals; rights; pluralism; culture; religion; bullfighting; indigenous; kosher; halal. 


\section{Sumario}

1. Cuestiones preliminares

2. Los animales y las tradiciones culturales: la tauromaquia

3. Los animales y la religión: la carne kosher y halal

4. Los animales y los pueblos indígenas

5. Conclusiones generales

Bibliografía

\section{Cuestiones preliminares}

El presente artículo aborda tres supuestos de análisis en relación con la ética animal ${ }^{1}$ y la pluralidad cultural de las comunidades humanas. Para ello, se realizará una breve exposición de los argumentos más relevantes sobre las correspondientes cuestiones. Las ideas principales se condensarán en una serie de conclusiones bajo distintos enfoques morales: el antropocentrismo ${ }^{2}$ fuerte (teoría indirecta de los deberes morales hacia los demás animales), el antropocentrismo débil (bienestarismo animal) y una defensa deontológica de los derechos de los animales ${ }^{3}$. Este esquema tiene como objetivo reflejar los puntos básicos de las distintas posturas en cada caso, mostrando una línea coherente en los razonamientos. Por lo general, se empieza con la exposición de los argumentos esgrimidos desde una visión antropocéntrica, de modo que le siguen una serie de objeciones que discuten los puntos dados previamente. Además, durante el desarrollo crítico se aportarán valoraciones personales con el fin de enriquecer el texto y el debate.

La composición de este trabajo intenta ofrecer al lector un marco general para mostrar las conexiones y, asimismo, las particularidades de los temas aquí tratados. Estos tres supuestos seleccionados tienen como propósito presentar las múltiples dimensiones que surgen respecto a la consideración moral hacia los animales no humanos. Si bien cada asunto ostenta una autonomía propia, se pueden hallar puntos comunes entre todos ellos. De tal manera, se emplearán argumentos similares pero con matices propios. Por último, señalar que estos ejemplos de estudio corresponden a diferentes estadios de reflexión, cuya problemática, a juicio del autor, va en ascenso. A saber, la tradición y las costumbres, la religión y, por último, la autonomía de los pueblos indígenas. Tres caras de la cultura humana que ejemplifican la complejidad y heterogeneidad que irradia la cuestión animal en su práctica. Pero antes de adentrarse en el examen los casos particulares, conviene precisar algunos conceptos previamente.

\subsection{Sobre la cultura}

Los individuos humanos están gobernados tanto por sus genes como por su cultura. De hecho, estamos «genéticamente predispuestos para el lenguaje y la comunicación simbólica» ${ }^{4}$. El ser humano «es, entre todos los animales, el único dominado por la cultura, por influencias aprendidas y transmitidas de una generación a otra» ${ }^{5}$. Buena parte del reino animal posee dos grandes procesadores de información: el genoma y el cerebro (junto al sistema nervioso). El primero es más estable pero menos moldeable. El segundo, mucho menos fiable pero se adapta con cierta facilidad a los cambios. La cultura forma parte de este último y los humanos (aunque no sean los únicos) han desarrollado notablemente esta capacidad de procesar información. Así es, «la especie humana ha pasado de la evolución biológica a la evolución cultural» ${ }^{6}$. Pero ¿qué es la cultura? Ciertamente, el significante cultura contiene varios significados y puede ser abordado desde diversos enfoques: histórico, antropológico, artístico o científico. En todo caso, aludimos a este concepto en relación con un determinado colectivo, lo que conlleva rasgos comunes de inclusión en el mismo que, a su vez, suponen la exclusión de otros diferentes. El colectivo se define socialmente por un aprendizaje acumulativo ${ }^{7}$, es decir, la cultura. Es lo distintivo de un grupo, lo característico: las costumbres, la educación, los ritos, la gastronomía, la política o los mecanismos de cooperación y de dominación, por ejemplo.

Desde un punto de vista etimológico, la palabra cultura va unida a la de cultivo, es decir, a la domesticación del entorno. Como indica Zygmunt Bauman, en «la esencia misma del concepto de "cultura" subyace una premonición o

\footnotetext{
${ }^{1}$ Se hará uso de los términos «animales no humanos» y «animales» como sinónimos.

${ }^{2}$ Conviene aclarar que se alude al antropocentrismo moral y no al antropocentrismo epistemológico.

${ }^{3}$ No se siguen los postulados de ningún autor o autora en particular. Si bien se apoya en la distinción entre agentes morales y pacientes morales, defendida por Tom Regan. Los animales no humanos sintientes se encontrarían dentro de esta última categoría de sujetos morales.

${ }^{4}$ Traducción propia de MONAGHAN, J. y JUST, P., Social \& Cultural Anthopology. A Very Short Introduction (Oxford 2000$) 35$.

${ }^{5}$ DAWKINS, R., El gen egoísta Extendido (Madrid 2017) 4.

${ }^{6}$ TURBÓN BORREGA, D., Evolución y adaptación del comportamiento, en Etología (Barcelona 2019) 157.

${ }^{7}$ Idem., 145.
}

106 Derecho Animal. Forum of Animal Law Studies, vol. 12/2 
una aceptación tácita de una relación social desigual, asimétrica, de una división entre los agentes y los receptores» ${ }^{8}$. La cultura, en cualquier caso, no es algo estanco, sino que se encuentra en constante transformación, en mayor o menor grado según el tipo de comunidad o grupo. La cultura tampoco es un término neutral. La tensión entre la tradición y el progreso es una cuestión que atraviesa este tipo de debates, porque tampoco el contenido de las costumbres o del progreso es imparcial. De modo que

Los códigos fundamentales de una cultura -los que rigen su lenguaje, sus esquemas preceptivos, sus cambios, sus técnicas, sus valores, la jerarquía de sus prácticas -fijan de antemano para cada hombre los órdenes empíricos con los cuales tendrá algo que ver y dentro de los que se reconocerá-. ${ }^{9}$

Lo importante, en todo caso, es reseñar que ninguno de estos elementos son per se positivos o negativos. Dejando de lado los problemas derivados de las múltiples acepciones de cultura, podríamos entender, entonces, la cultura como el conjunto de modos de vida, tradiciones y costumbres, así como los conocimientos propios de un grupo social ${ }^{10}$, sean estos científicos, religiosos, artísticos o filosóficos.

En definitiva, la cultura no es un fenómeno aislado, muy al contrario, es un conjunto complejo de costumbres y pensamientos de origen dispar que convergen en un mismo lugar y tiempo. Las falsas creencias, la tradición popular, las necesidades (individuales y colectivas), el conocimiento científico y la ética se mezclan y se disputan el relato.

Existen tantas culturas en el planeta que sería imposible hablar de una cultura humana. Con el proceso de globalización, se ha acelerado y multiplicado el contacto entre las distintas culturas. Este acercamiento no ha sido en condiciones equitativas, lo que ha llevado a que una determinada cultura, la denominada occidental, se imponga al resto. Por eso, cabe aclarar que se asumirá una defensa parcial de la hermeneútica diatópica, es decir, «de la idea de que todas las culturas son incompletas y, por tanto, pueden ser enriquecidas por el diálogo y por la confrontación de otras culturas $\gg{ }^{11}$, sin caer en ningún caso en el relativismo moral. No se trata, pues, de uniformar un tipo de vida, sino más bien del respeto de todas las culturas dentro de un marco de entendimiento con los otros. Lo que para Luis Villoro es una verdadera tolerancia entre culturas autónomas ${ }^{12}$, una tolerancia positiva. Ello no conlleva un rechazo a los juicios morales, pues estos se realizarían dentro de las buenas razones, no de la imposición dogmática ni la apelación a nociones puramente metafísicas como la dignidad (humana o animal) o el valor inherente.

\subsection{Los animales no humanos y el multiculturalismo}

Antes de adentrarnos en el estudio de los casos, cabe reseñar que existen varios artículos académicos en relación con el multiculturalismo y los animales. En este apartado se hará mención a dos, sin perjuicio de la exposición de otros durante el presente artículo, con el objetivo de ofrecer un esbozo del estado de la cuestión. El artículo Is Multiculturalism Bad for Animals ${ }^{13}$, de Paula Casal, pone de relieve que existen innumerables expresiones culturales que vulneran la vida y la integridad física y psíquica de los animales no humanos. La filósofa resalta el caso de la santería, la tauromaquia o, en menor medida, los métodos de carnicería shechita y dabiha. Tras examinar estos supuestos, concluye que «deberíamos negar a las minorías las exenciones perjudiciales para las mujeres, niños o animales, lo que no implica que debamos rechazar otras formas de especial consideración» ${ }^{14}$. La crueldad hacia los más débiles, hacia los animales, no se puede justificar a pesar de que estos actos sean realizados por grupos desfavorecidos. Así las cosas, en 2017, Maneesha Deckha publicó Is Multiculturalism Good for Animals? ${ }^{15}$, donde critica el doble estándar o rasero moral del discurso occidental. Esta autora realiza una comparación con las culturas del sur global, como son la hindú, la budista o la jainista; del mismo modo, destaca las políticas bienestaristas de India en relación con determinados animales. Deckha no discute que el multiculturalismo pueda ser peligroso para los animales, pero se opone al marco que presume tensiones entre la diversidad cultural y los derechos de los animales. El punto esencial que se defiende es que el racismo y el antropocentrismo están interconectados, de modo que «un compromiso multicultural/antirracista tiene el potencial para hacernos ser conscientes de las injusticias del antropocentrismo» ${ }^{16}$, pues las perspectivas del multiculturalismo estimulan el pensamiento y el hacer sobre los animales para desarrollar un interés, una empatía y una solidaridad $\operatorname{con}_{\text {ellos }}{ }^{17}$.

Efectivamente, no existe una confrontación entre ambas autoras. Más bien abarcan discursos complementarios. Es más, no solo el racismo está emparentado con el especismo, sino que el modelo de vida patriarcal y machista tiene importantes puntos de conexión, como así destaca Alicia H. Puleo ${ }^{18}$ o Angélica Velasco ${ }^{19}$ desde el ecofeminismo crítico. El multiculturalismo, siempre que no se juzgue desde un prisma etnocéntrico, no es por sí mismo un factor bueno o malo

\footnotetext{
${ }^{8}$ BAUMAN, Z., Vida líquida (Barcelona 2009) 74.

${ }^{9}$ FOUCAULT, M., Las palabras y las cosas (Ciudad de México 2010) 13.

${ }^{10}$ Definición de la palabra cultura según el Diccionario de la lengua española (DLE): «3. f. Conjunto de modos de vida, costumbres y grado de desarrollo artístico, científico, industrial, en una época, grupo social, etc.». Página Web: https://dle.rae.es/cultura?m=form

${ }^{11}$ DE SOUSA SANTOS, B., El milenio huérfano. Ensayos para una nueva cultura política (Madrid 2005) 177.

${ }^{12}$ VILLORO, L., Los retos de la sociedad por venir (México D.F. 2007) 183.

${ }^{13}$ CASAL, P., Is Multiculturalism Bad for Animals?, en The Journal of Political Philosophy, 11/1. (2003).

${ }^{14}$ Traducción propia de CASAL, P, Is Multiculturalism Bad for Animals?, 22.

${ }^{15}$ DECKHA, M., Is Multicuturalism Good for Animals?, en Animals, Race, and Muticulturalism (London 2017).

${ }^{16}$ Traducción propia de DECKHA, M., Is Multicuturalism Good for Animals?, 87.

${ }^{17}$ Ibid., 82.

${ }^{18}$ PULEO, A. Ecofeminismo para otro mundo posible (Madrid 2019).

${ }^{19}$ VELASCO SESMA, A., La ética animal. ¿Una cuestión feminista? (Madrid 2019).
} 
para los intereses de los animales. Como se ha indicado anteriormente, prácticamente todas las culturas someten a los animales y se aprovechan de ellos de un modo u otro. La cuestión entonces sería dirimir cada supuesto de conflicto en concreto. A pesar de que Europa (el considerado paradigma del bienestarismo animal) ha mejorado su legislación y consideración moral hacia los animales, la normativa europea no se acerca ni de lejos a los mínimos propuestos por la teoría de los derechos de los animales. Es más, el control y la garantía de su legislación es muy deficiente por parte de los Estados miembros. Así pues, si se propone un análisis crítico de otras culturas, parece adecuado, en primer lugar, enjuiciar en profundidad la propia.

\section{Los animales y las tradiciones culturales: la tauromaquia}

Los animales han estado presentes en todas las culturas. Su rol ha sido variopinto, han sido alzados como dioses o símbolos de la patria, pero también han sido señalados como portadores de los males del mundo. Así, por ejemplo, «los hindúes veneran a las vacas porque son el símbolo de todo lo que está vivo. [...] Así no hay mayor sacrilegio para un hindú que matar a una vaca» ${ }^{20}$, llegando incluso a considerar a las vacas como miembros de la familia. De otro lado, son objeto de sacrificio y ofrendas a los dioses, como es el caso de la santería o el festival Gadhimai, en Nepal, donde se ejecutan a miles de animales, cuya «cifra récord se alcanzó en 2009, cuando se sacrificaron a más de medio millón de búfalos, cabras, pollos y otros animales, dando a la festividad el título de mayor matanza ritual del mundo» ${ }^{21}$.

Sin embargo, no solo la religión ha justificado el maltrato para con los animales, sino también la mera tradición o costumbre del lugar. De hecho, en Europa, desde la Baja Edad Media hasta principios del siglo XVIII, eran populares los espectáculos públicos donde se torturaban osos, toros, perros, gallos y otros animales ${ }^{22}$. La mayoría de países europeos han ido eliminado estas prácticas de forma progresiva. La tauromaquia ${ }^{23}$ es una excepción a esta tendencia abolicionista. La modalidad más conocida de esta es la corrida de toros y, por tanto, se hará más énfasis en ella. A continuación se analizarán diferentes argumentos a favor y en contra de esta tradición española.

\subsection{El argumento de la tradición cultural}

Es probable, señala Marta Vericat, que en el siglo IX ya hubiese fiestas taurinas, pero es «En el siglo XIII [cuando] aparecieron las primeras disposiciones jurídicas sobre las fiestas de toros en forma de ordenanzas y acuerdos municipales» ${ }^{24}$. Aunque las corridas de toros tal como se conocen no tienen un pasado tan lejano. En el siglo XVIII los toreros empiezan ir a pie y mediante la Real Orden de 13 de junio de 1928 se eliminan las banderillas de fuego y se introducen nuevas normas. Ahora bien, apelar a la mera tradición es un argumento insuficiente. Las costumbres son parte central de una determinada cultura, pero este hecho no puede servir de pretexto para justificar atrocidades. Son numerosos los ejemplos basados en la dominación y la opresión de un grupo o de un sistema de valores, como el patriarcado o el supremacismo étnico. La mutilación genital femenina o los matrimonios concertados de menores son claros ejemplos de ello.

Los autores protaurinos son conscientes de este hecho. Francis Wolff confiesa que «los antitaurinos lo tienen fácil para responder que la tradición no es un argumento y que la mayor parte de los grandes progresos de la civilización se han hecho contra costumbres bien arraigadas ${ }^{25}$. En esta línea, Fernando Savater admite que «la raigambre tradicional no legitima sin más las fiestas, ni comportamientos sociales ni nada de nada ${ }^{26}$. Y, sin embargo, curiosamente el propio Savater firmó el Manifiesto en defensa de la Tauromaquia en 2010, donde declaraba públicamente su apoyo «a la Fiesta como una de las señas de identidad de nuestro país y nuestra cultura. Los toros forman parte de nuestro patrimonio cultural y como tal deben ser respetados y protegidos por el Gobierno de la nación» ${ }^{27}$, si bien se apelaba también a otras razones de carácter artístico o ecológico. En este sentido, huyendo de una connotación arcaica, Wolff asevera que «la corrida de toros no ha dejado de desarrollarse en España a lo largo de todo el siglo XX y está más viva que nunca» ${ }^{28}$. Esta huida hacia adelante se debe a la asociación de estos espectáculos a la denominada España negra. Frente a la Ilustración, que alumbró a varios países europeos, España se aisló,

hizo de la diferencia su marca y, con un equivocado orgullo, convirtió en seña de identidad aquello que otros países ya habían logrado superar. [...] Y así es como los espectáculos taurinos, por distintos intereses, pasaron a ser un artificial santo y seña de lo español, y como tal ha llegado hasta nuestros días. ${ }^{29}$

\footnotetext{
${ }^{20}$ HARRIS, M., Vacas, cerdos, guerras y brujas (Madrid 2007) 15-16.

${ }^{21}$ LA VANGUARDIA, El mayor sacrificio religioso de animales del mundo sigue adelante a pesar de las prohibiciones, en La Vanguardia, 5 de diciembre de 2019. Página web: https://www.lavanguardia.com/natural/20191205/472062751285/mayor-sacrificiodel-mundo-matanza-animal-festival-gadhimai-nepal-india.html [Última consulta: 22 de noviembre de 2020].

${ }^{22}$ MOSTERÍN, J., A favor de los toros (Pamplona 2010) 61.

${ }^{23}$ Se entiende por tauromaquia todo espectáculo de lidia de toros, es decir, de esquiva o burla, que usualmente termina con la muerte del animal.

${ }^{24}$ VERICAT, M., Filosofía y toros. Un debate ético (Barcelona 2018) 38-39.

${ }^{25}$ WOLFF, F., 50 razones para defender la corrida de toros (Córdoba 2019), 59-60.

${ }^{26}$ SAVATER, F., Tauroética (Madrid 2011) 81.

${ }^{27}$ MUNDOTORO, Fernando Savater: "Los toros deben ser respetados y protegidos por el Gobierno, en AS, 25 de febrero de 2010. Página Web: https://as.com/diarioas/2010/02/25/toros/1267052401_850215.html [Última consulta: 22 de noviembre de 2020].

${ }^{28}$ WOLFF, F., 50 razones para defender la corrida de toros, 53-54

${ }^{29}$ CODINA SEGOVIA, J. I., Pan y toros. Breve historia del pensamiento antitaurino español (Madrid 2018) 18-19.

108 Derecho Animal. Forum of Animal Law Studies, vol. 12/2
} 
Aunque se ha de aclarar que hubo varios intentos de prohibir la fiesta de los toros en España, todas sin éxito. Desde las Leyes de Partida, del rey Alfonso X hasta el reinado de Carlos III, pasando por la bula De salutes gregis dominici, de 1567, promulgada por el papa Pío V. Como muestra Codina, en su libro Pan y Toros, surgen al mismo tiempo tanto los simpatizantes de los espectáculos taurinos como sus detractores. No obstante, se ha intentado vincular continuamente la tradición de los toros al sentimiento patriótico.

Comúnmente se acude a la idea de que la tauromaquia es un festejo propio de España o de una determinada parte del territorio nacional. Por ello, se denomina la fiesta nacional a las corridas de toros, aunque el actual toreo se extendió a otras partes del mundo «a pesar de haber nacido en algunas regiones de España (Andalucía, Castilla o Navarra). Y todas las poblaciones que adoptaron este ritual y sus valores los integraron en sus culturas y tradiciones particulares $\rangle^{30}$. Como se ha indicado anteriormente, en rigor, las corridas de toros y el resto de espectáculos taurinos no han sido algo propio de lo español, pues «en la Italia del siglo XIV [...] las corridas de toros eran muy frecuentes» ${ }^{31}$ y desde el siglo XII en Inglaterra «se ataba al toro a un poste y se azuzaba a los bull-dogs a morderlo en sus partes blandas y al toro a matar a coces a los perros, todo ello en un ruedo con gradas para los espectadores ${ }^{32}$. Sin embargo, a diferencia de España, otros países europeos dejaron de lado este tipo de celebraciones sangrientas a la llegada de las ideas ilustradas. Así, el Parlamento británico prohibió este tipo de espectáculos en $1835^{33}$.

Las razones que apelan a la tradición cultural tienen un arraigo de carácter político, en tanto que «Existe la tendencia nacionalista y rancia que apela al criterio de la tradición con orgullo con el fin de defender la perpetuidad de la tauromaquia ${ }^{34}$. Siendo así que, tras la prohibición de las corridas de toros en territorio catalán en 2010 , se consideró «un atentado contra la unidad de la nación española. El mismo argumento que se utiliza en México o en Colombia cuando se apela a la tradición, que en el continente americano se remonta como poco hasta $1535 »^{35}$. Esta prohibición en el territorio catalán en 2010 no estuvo exenta de polémica, pues la misma ley permitía otros festejos taurinos, de igual crueldad, como los correbous y los toros embolados, típicos de ciertas zonas de Cataluña. La identidad cultural es a menudo una herramienta moldeable por el discurso político. En ocasiones se explicita y otras veces a través de medios más sutiles. En política todo asunto moral puede servir para otros fines oblicuos, y la cuestión animal no es la excepción.

Por tanto, independientemente de los debates políticos, la tradición no es un argumento de peso que pueda aducirse a la cuestión del pluralismo cultural. Además, «La cultura no es una realidad estática, sino dinámica, y cambia constantemente, sometida a diversas influencias, una de las cuales es la crítica racional» ${ }^{36}$. Lo fundamental, de nuevo, sería reconocer las tradiciones que aportan valores positivos a la comunidad y rechazar aquellas que embrutecen la conducta humana y debilitan la compasión o la sensibilidad hacia otros seres capaces de sufrir. Pues, cuanto menos, es un «mal síntoma» que produce y reproduce una cultura de la violencia que afecta a nuestra forma de relacionarnos con el mundo y el resto de seres sintientes, incluidos los humanos.

\subsection{El argumento estético}

Francis Wolff defiende que el arte del toreo consiste en crear belleza, «supone elegancia, armonía de movimientos, perfección de formas, equilibrio de volúmenes. El toreo crea formas, obras humanas a partir del caso, es decir, la acometida natural del toro ${ }^{37}$. De tal manera que toda la liturgia que se despliega en la plaza de toros es propia de una expresión artística: la coreografía de los implicados, la vestimenta que se porta y, obviamente, los movimientos del torero. La tauromaquia sería un arte original que funde el clasismo y la modernidad. Es más, según este entender, buena parte de «las artes cultas han abandonado la representación, para transformarse en artes de la actuación única y de la presentación directa ${ }^{38}$. Por tanto, la corrida de toros no representa el cuerpo o la muerte, sino que el toreo es el propio cuerpo y la propia muerte en escena. El toreo sería un arte original porque «añade la dimensión que ninguna otra arte podrá nunca dar: la dimensión de la realidad ${ }^{39}$. Como fiesta, su estética está ligada a una comunidad, a lo público. Pero no solo se trataría de un arte en sí mismo, sino que genera arte en otras ramas como en lo pictórico, el cine o la literatura. Inspira y ha inspirado a multitud de artistas en diferentes épocas y contextos. Los defensores de la tauromaquia suelen aludir a las obras de Lorca o Picasso ${ }^{40}$. De hecho, según estos autores, como arte no puede afirmarse que sea cruel, en tanto que no se disfruta del padecimiento del animal, sino del festejo y todo lo que le rodea. En palabras del filósofo Gustavo Bueno:

lo esencial de la fiesta del toro no es, en absoluto, el matar al animal, el destrozarle, el hacerle sufrir dolor, porque

\footnotetext{
${ }^{30}$ WOLFF, F., 50 razones para defender la corrida de toros, 59.

${ }^{31}$ CODINA SEGOVIA, J.I., Pan y toros, 18

${ }^{32}$ MOSTERÍN, J., A favor de los toros, 57.

33 VERICAT, M., Filosofía y toros, 44.

${ }^{34}$ Idem., 81.

${ }^{35}$ CASTRO, E., Ética, estética y política. Ensayos (y errores) de un metaindignado (Barcelona 2020) 200.

${ }^{36}$ MOSTERÍN, J., A favor de los toros, 95.

${ }^{37}$ WOLFF, F., 50 razones para defender la corrida de toros, 72 .

${ }^{38}$ Idem., 73.

${ }^{39}$ Idem., 74.

${ }^{40}$ Curiosamente el pintor y grabador Francisco de Goya ha sido mencionado como gran baluarte de la tauromaquia a razón de alguna de sus obras. Lo cierto es que, como demuestra Juan Ignacio Codina, Goya, como ilustrado que era, retrató la crueldad y la brutalidad del toreo. Es decir, fue una víctima de la taurinización. Léase CODINA SEGOVIA, J.I., Pan y toros, 84-88.
} 
ninguna de estas finalidades son objetivo del toreo, ni del torero, ni del que ve los toros. El animal es tratado con todo respeto. ${ }^{41}$

Por eso, prosigue el autor, que estamos ante un arte que descarta la idea de tortura, «Decir que la tortura no es cultura es partir del principio. Además de no entender lo que es la idea de cultura, no entender nada»»> ${ }^{42}$. En esta línea, podría afirmarse que guste o no es cultura, porque es parte de las costumbres sociales de un determinado lugar. Por su parte, Fernando Savater sostiene que «la tortura también es cultura, qué va a ser si no, lo mismo que los misiles tierraaire o el espionaje industrial» ${ }^{43}$. Cuestión distinta es que pueda rechazarse por otros motivos. Para el autor donostiarra, en el toreo «hay códigos de honor, reglas de arte y celebraciones simbólicas que pueden no compartirse pero que nadie puede arrogarse la autoridad moral para descalificar sin más» ${ }^{44}$. Por tanto, la tortura es cultura y, en concreto, es arte. No se trata de un mero deporte, pues, en realidad, no hay una igualdad entre los combatientes, ya que el final se sabe de antemano, pero aunque desigual es una lucha leal, donde el «toro se transforma en el único adversario que el hombre encuentra digno de él» ${ }^{45}$ y se le da muerte «conforme a su naturaleza de animal bravo [...] una muerte en lucha contra aquél que cuestiona su propia libertad, es decir, contra aquel ser vivo que le disputa el terreno de supremacía. Éste es el drama que se muestra en el redondel» ${ }^{46}$. Un arte en forma de «ballet dramático juntamente sutil y brutal, tutelado por un reglamento cuyo cumplimiento el público exige y que aplica la autoridad competente» ${ }^{47}$. Se podría argumentar, además, que los artículos 22 y 27 de la Declaración Universal de los Derechos Humanos recogen que la satisfacción de los derechos culturales es de suma importancia para el desarrollo de la personalidad y que toda persona tiene el derecho de participar en la vida cultural de su comunidad.

De lo dicho se pueden encontrar varias objeciones. Sin embargo, cabe aclarar lo siguiente. Tras la irrupción de las vanguardias y el posmodernismo, es difícil dar una noción unívoca de arte. Las obras plenamente abstractas supusieron una concepción distinta del artista. La técnica y los cánones formales pasaron a un segundo plano. Bajo este paradigma, lo tradicional y lo contemporáneo son compatibles pero muy distantes. Ambas visiones conviven y, a veces, se entrelazan. Tras el pop art, es decir, la producción industrial y mercantilista de la obra, el arte llega a concebirse como una función de la vida en sí misma ${ }^{48}$. La innovación es el requisito elemental de lo artístico. El carácter representativo o de recreación irá perdiendo interés en algunas corrientes a favor de una realidad en clave artística. Véase el ejemplo del supuesto artista que dejó morir de inanición a un perro en una galería de arte en Nicaragua ${ }^{49}$. Así pues, no parece que el debate sobre la consideración artística de la corrida de toros sea muy fructífero ante la diversidad de criterios en el contexto actual. Si entendemos el arte como una cuestión altamente subjetiva, defender el toreo como obra artística tiene la misma solidez argumentativa que negarla. Algunos autores, como Francisco de Lara y Olga Campos, parten de la premisa que «el arte no puede hacerse a costa del sufrimiento animal» ${ }^{50}$, invalidando así cualquier argumento sobre la supuesta relevancia artística de la tauromaquia. En el arte, como en la vida social, no todo vale. El juego simbólico que pueda desprenderse del toreo puede hallarse en otras representaciones. Ciertamente, el espectáculo taurino forma parte de la cultura, como hecho fáctico, en tanto que se practica y se apoya por una parte de la población. Aunque las corridas de toros «nunca han formado parte del canon de las bellas artes, no por eso dejan de constituir una tradición cultural» ${ }^{51}$. En esta línea, el Tribunal Supremo, en una reciente sentencia de 16 de febrero de 2021, afirma que la faena de un torero no puede considerarse una obra de propiedad intelectual. El tribunal afirma que la coreografía del toreo no concuerda con las características recogidas en la Ley de Propiedad Intelectual de 1996. Es decir, la identificación precisa y objetiva de los movimientos y formas, que facilita la posibilidad de volver a reproducirse e identificar «en qué consiste la creación, tanto a terceras personas como a las autoridades encargadas de la protección de las obras de propiedad intelectual. No ocurre lo mismo en la faena de un torero», pues «resulta muy difícil identificar de forma objetiva en qué consistiría la creación artística original» ${ }^{52}$.

Por otra parte, la expresión «la tortura no es cultura»es, a todas luces, una propuesta crítica. No es un lema descriptivo o una formulación académica, sino reivindicativa. Propio de los eslóganes de los activismos sociales. Utilizar tal frase para ejemplificar la falta de conocimiento de los antitaurinos es, cuanto menos, un descuido intelectual, un pretexto para moldear un hombre de paja al otro lado del debate. Con el citado lema se pretendería reivindicar que cualquier expresión cruel no debería considerarse arte o bien no sería recomendable que formara parte de nuestra cultura. Y ¿por qué? Porque los actos violentos cuyo fin o medio es dañar a un otro anulan las virtudes de la compasión, la empatía o la sensibilidad. Esta dinámica de la cultura de la crueldad afecta especialmente a los menores, pues es sabido

${ }^{41}$ BUENO, G., Sobre los toros, en Teselas. 36. Página Web: http://fgbueno.es/med/tes/t036.htm [Última consulta: 22 de noviembre de 2020].

42 Idem.

${ }^{43}$ SAVATER, F., Tauroética, 17.

${ }^{44}$ Idem., 75.

${ }^{45}$ WOLFF, F., 50 razones para defender la corrida de toros, 35 .

${ }^{46}$ Idem., 37.

${ }^{47}$ SAVATER, F., Tauroética, 69.

${ }^{48}$ HOLZWARTH, H.W., Arte moderno (Colonia 2016) 13.

${ }^{49}$ MUÑOZ GÓMEZ. F., El artista que dejó morir de hambre a un perro en en una galería de arte, en ABC blogs, 7 de agosto de 2015. Página Web: https://abcblogs.abc.es/archivos-desclasificados/2015/08/07/matar-hambre-perro/ [Última consulta: 24 de noviembre de 2020].

${ }^{50}$ LARA, F. y CAMPOS, O., Sufre, luego importa. Reflexiones éticas sobre los animales (Madrid 2015) 102.

${ }^{51}$ MOSTERÍN, J., A favor de los toros, 23.

${ }^{5}$ Sentencia núm. 82/2021, de 16 de febrero, de la Sala de lo Civil del Tribunal Supremo, en

https://www.poderjudicial.es/search/TS/openDocument/7f653067celb59ff/20210301 [Última consulta: 1 de marzo de 2021].

110 Derecho Animal. Forum of Animal Law Studies, vol. 12/2 
que la infancia es un periodo vital de enorme plasticidad del cerebro y la inmensa mayoría de ellos no poseen una comprensión adecuada sobre la trascendencia de los hechos culturales y sociales. En este sentido, el Comité de Derechos del Niño ha recomendado a España prohibir a los menores de edad la participación y la asistencia a este tipo de espectáculos ${ }^{53}$. Normalizar este tipo de espectáculos conlleva una educación desvirtuada, máximo cuando estos menores presencian actividades violentas a modo de formación. Disminuyendo así sus capacidades empáticas y compasivas. Como diría el conocido filósofo y pedagogo José Antonio Marina, «las emociones influyen en el conocimiento, pero el conocimiento influye en las emociones» ${ }^{54}$. Ahora bien, ¿es la tauromaquia realmente un espectáculo cruel? Sin entrar en la discusión etimológica de la palabra ${ }^{55}$, pues la crudeza no descarta la crueldad, «La crueldad activa consiste en el maltrato doloroso e intencional de una criatura sensible, produciendo, alargando e incrementando su dolor sin necesidad alguna. Este aumento deliberado e innecesario del sufrimiento de la víctima es la esencia de la crueldad ${ }^{56}$. Si acudimos a las acepciones que nos ofrece el Diccionario de la lengua española encontramos que cruel es tanto el que «se deleita en hacer sufrir o se complace en los padecimientos ajenos» o también «sangriento, duro, violento». En su primera acepción puede surgir cierta controversia porque si bien los aficionados a la tauromaquia no disfrutan del sufrimiento en sí mismo, sí que se deleitan indirectamente de los padecimientos del animal. Tanto es así que una corrida sin sangre ni muerte perdería su sentido de ser, pues «es el instante de la verdad» ${ }^{57}$ y «el fin necesario de la ceremonia sacrifical» ${ }^{58}$. De hecho, tras la declaración de la tauromaquia como patrimonio cultural inmaterial por parte del Estado español en 2013, la estrategia de quienes han querido abolir la corrida de toros es dejar irreconocible a este espectáculo. Así, el Parlament balear «optó por regular minuciosamente los espectáculos taurinos eliminando sus elementos más sangrientos e inhumanos» ${ }^{59}$. Respecto a la segunda acepción, no cabe duda de su pertinencia. Así pues, hay buenas razones para calificar los actos taurinos como crueles. Y estos forman parte de una cultura de la violencia que debe evitarse en una sociedad que pretenda aspirar a las virtudes mencionadas anteriormente, ya sea en el arte o en la vida cotidiana de las personas.

Las reiteradas afirmaciones de que el toro es tratado con respeto ${ }^{60}$ solo visibilizan la atrofia moral de lo que entienden por respeto. Los autores protaurinos aluden a cierta mística de la honradez y del respeto en el duelo del torero y el toro. Realmente, es difícil defender el respeto como la anulación de la libertad del otro, de causarle heridas, sufrimiento e, incluso, la muerte. La aclamación pública a un ser que ni siquiera posee los códigos de honor para entender ese significado es un criterio claramente insuficiente. Criterio que ni siquiera podría justificarse en relación con los gladiadores romanos, pues (al igual que los toros) no eran libres en la elección. En definitiva, el acto de respetar es como mínimo no hacer sufrir. También se recalca la admiración y la fascinación por el toro, pero como se ha visto, estas emociones subjetivas se pueden traducir en consecuencias negativas para el sujeto de tal admiración o fascinación. Se produce, por ende, una banalización de la crueldad, una distorsión de lo trascendental del sufrimiento. De tal manera, la denominan la fiesta de los toros. Así es, «ciertamente todo puede ser arte, incluido los toros, pero sin olvidar que esto solo se conseguiría a costa de vaciar de todo contenido el término arte ${ }^{61}$, ya que se habilitaría la carnicería como expresión artística. Si el arte nos identifica como sociedad, la pregunta orbita en torno al tipo de sociedad se quiere formar. Por último, el derecho a la cultura que proclama la Declaración Universal no es una hoja en blanco ni hace referencia a un aspecto en particular, sino al acceso y participación a la cultura en general que posee una comunidad.

\subsection{El argumento ético}

Los protaurinos centran su defensa de la tauromaquia en la idea de las diferentes sensibilidades. Francis Wolff escribe que «Sólo hay un argumento contra las corridas de toros y no es verdaderamente un argumento. Se llama sensibilidad ${ }^{62}$. Es respetable, por tanto, que ciertas personas les hiera o no puedan soportar ver a un animal sufriendo, pero es simplemente un tipo de sensibilidad más que no debe ser impuesta al resto de la sociedad. En esta línea, Fernando Savater expone que «Yo no practico la caza ni la pesca [...] ni sería capaz de trabajar en un matadero: conozco lo que repugna a mi sensibilidad, pero no tendría la arrogancia de convertirlo en norma ética impuesta a todos» ${ }^{63}$. Entendiendo que esta idea es inaplicable a los seres humanos, cabría preguntarse ¿por qué no es relevante el sufrimiento del animal si padece de forma similar al humano? La respuesta se resumiría mediante la siguiente aseveración: «Quien se complace en el sufrimiento de los animales no viola una obligación moral con ellos, que no existe, sino que renuncia a su propio perfeccionamiento moral y se predispone a ejercer malevolencia contra sus semejantes» ${ }^{64}$. Excluyendo así de la ética la

\footnotetext{
${ }^{53}$ Véase las recomendaciones a España del Comité de los Derechos del Niño (CRC/C/ESP/CO/5-6), de 2 de febrero de 2018, en https://tbinternet.ohchr.org/Treaties/CRC/Shared\%20Documents/ESP/CRC_C_ESP_CO_5-6_30177_E.pdf [Última consulta: 4 de enero de 2021].

${ }^{54}$ MARINA, J.A., La inteligencia fracasada. Teoría y práctica de la estupidez (Barcelona 2008) 53.

${ }^{55}$ Fernando Savater afirma que la significado etimológico de crueldad es crudo y, por tanto, defiende que en la tauromaquía hay crudeza pero no crueldad. Mientras que Jesús Mosterín indica que el origen de la palabra crueldad viene de sangre derramada.

${ }^{56}$ MOSTERÍN, J., A favor de los toros, 23-24.

${ }^{57}$ WOLFF, F., 50 razones para defender la corrida de toros, 33.

58 Idem., 34.

${ }^{59}$ CODINA SEGOVIA, J.I., Pan y toros, 207.

${ }^{60}$ Véase los libros citados de Francis Wolff y Fernando Savater, o la anterior cita de Gustavo Bueno.

${ }^{61}$ LARA, F. y CAMPOS. O., Sufre, luego importa, 106.

${ }^{62}$ WOLFF, F., 50 razones para defender la corrida de toros, 13.

${ }^{63}$ SAVATER, F., Tauroética, 55.

${ }^{64}$ Idem., 34.
} 
consideración moral hacia los animales, en tanto que niegan que su sufrimiento sea relevante. Asimismo, rechazan que estos posean intereses y autonomía. Para Savater sería «prestarles a lo Disney capacidades, vicios y virtudes de los humanos» ${ }^{65}$. De tal modo que la ética versaría sobre el reconocimiento de la excepcionalidad humana, de su singular autonomía y raciocinio, ajustando su conducta a los juicios de valor que es capaz de hacer. Una ética de corte kantiano, en pocas palabras. Además, ligan este argumento con la negación de la crueldad de la tauromaquia, pues como declara Francis Wolff: «No admito que sea un espectáculo cruel, puesto que la crueldad supone el placer que se obtiene de una víctima» ${ }^{66}$. En esta línea, otro defensor de la corrida de toros es el filósofo Víctor Gómez Pin, el cual arguye razones parecidas a la de otros autores, pero la representa como «una sobria escuela de vida» donde el «el toreo es precioso. Y perderlo sería tanto perder una referencia ética como estética. Cuando es un espectáculo castizo y casposamente costumbrista su desaparición no sería una pérdida» ${ }^{67}$.

El tema taurino también se aborda, aunque de forma soslayada, desde la ética ecológica. En el mencionado Manifiesto a favor de las corridas de toros firmado en 2010 se afirmó que «Destacamos los valores ecológicos del toro de lidia como especie única y creación cultural del hombre, que lo ha seleccionado durante siglos. Y también como protector de un espacio natural que pervive gracias a su presencia: la dehesa» ${ }^{68}$. Del mismo modo, Wolff mantiene que a través de la fiesta de los toros se preserva la biodiversidad y que para salvar «la especie (o la variedad) es necesario "sacrificar" algunos toros en el ruedo» ${ }^{69}$.

Antes de realizar las objeciones correspondientes a los principales argumentos, podríamos aclarar este último punto sobre el ecologismo. Apuntar que «el llamado toro bravo no constituye una especie, ni siquiera una subespecie [...] Toda la retórica y mitología de la tauromaquia se basa en la más supina ignorancia de lo que realmente es un toro» ${ }^{70}$. En todo caso, desde una perspectiva de los derechos de los animales, la biodiversidad, en principio, no es un argumento de peso frente a los derechos básicos de los titulares de derecho. Conviene aclarar, además, que la biodiversidad puede convertirse fácilmente en un argumento puramente estético y antropocéntrico, salvo que la medida ecológica correspondiente pondere los intereses de los individuos implicados y sus derechos. Añadir, por lo demás, que el argumento ecológico en los términos que plantean los protaurinos tiene difícil encaje con los valores de los movimientos ecologistas, que podrían justificar la muerte de animales por un bien mayor como es la conservación de la biodiversidad y no a razón de un mero espectáculo humano.

Respecto al resto de argumentos expuestos se puede objetar, en primer lugar, que se confunden los términos de crueldad y sadismo, pues en el acto cruel no es necesario obtener placer de quien lo ejecuta o visualiza. De otra parte, alegar que el toreo es una cuestión de sensibilidades es acercarse peligrosamente al relativismo moral. Los límites que ponen estos autores son relativos a la especie, no a la capacidad de sentir y sufrir. Independientemente de que se esté a favor o en contra de la consideración moral igualitaria entre todos los seres sintientes, lo cierto es que no sentir compasión por un ser que está sufriendo es un hecho moral, porque parece razonable procurar evitar un dolor innecesario a todo ser sensible. El concepto compasión procede del prefijo con, que significa convergencia o junto a, y la palabra patior, que es sufrimiento o pena. Siendo así extensible tal sentimiento hacia cualquier ser capaz de sufrir o padecer. Por otro lado, la ética se encarga, entre otras cosas, de reflexionar sobre las mores, las costumbres, la moral. En términos generales, la ética versa sobre el bien y el fundamento de sus valores ${ }^{71}$, de la conducta de los seres capaces de entender una idea abstracta y concreta del bien y el mal, de lo correcto e incorrecto en de las acciones humanas frente a otros. En concreto, entendemos como ética a esa disciplina filosófica que constituye una reflexión de segundo orden sobre los problemas morales. La pregunta básica moral sería entonces "qué debemos hacer", mientras que la cuestión central de la Ética sería más bien “¿por qué debemos?”, es decir, “qué argumentos avalan y sostienen el código moral que estamos aceptando como guía de conducta?". ${ }^{72}$

También se puede remarcar que «la palabra "ética" puede entenderse en el amplio sentido que tenía en la antigüedad, a saber, en el sentido de la pregunta amplia por la acción, o la vida buena o recta» ${ }^{73}$. Y la cuestión animal forma parte de la ética aplicada, pues se centra en un asunto concreto de los juicios morales. De modo que el objeto de la ética y la moral no tiene por qué ser necesariamente un individuo humano. Habría que preguntarse de forma imparcial cuáles son los atributos que hacen que un sujeto sea moralmente relevante. Parece razonable, por tanto, incluir a los seres capaces de sentir placer y dolor, a pesar de que existan diversas formas de enfocar la cuestión. En este sentido, la relación que los humanos tienen con el resto de animales es de una importancia ética de primer orden. Por ello, parecería ser erróneo el planteamiento de Savater en tanto que «la barbarie no consiste en tratar con inhumanidad a los animales, sino en no distinguir el trato que se debe a los humanos y el que puede darse a los animales» ${ }^{74}$. Más bien al contrario, la barbarie (lo cruel, lo fiero, lo falto de civilidad) consiste en no apreciar la importancia moral de nuestra relación con los

\footnotetext{
${ }^{65}$ Idem., 25.

${ }^{66}$ WOLFF, F., 50 razones para defender la corrida de toros, 47.

${ }^{67}$ GÓMEZ PIN, V., (entrevistado por Agencia EFE) Víctor Gómez Pin: "Sin el toreo perderíamos una referencia ética y estética"», en La Razón, 15 de mayo de 2012. Página web: https://www.larazon.es/historico/6444-victor-gomez-pin-sin-el-toreo-perderiamosuna-referencia-etica-y-estetica-JLLA_RAZON_457940/ [Última consulta: 24 de noviembre de 2020].

${ }^{68}$ MUNDOTORO, Fernando Savater: "Los toros deben ser respetados y protegidos por el Gobierno.

${ }^{69}$ WOLFF, F., 50 razones para defender la corrida de toros, 41-42.

${ }^{70}$ MOSTERÍN, J., A favor de los toros, 16.

${ }^{71}$ Véase en el Diccionario de la lengua española. Página Web: https://dle.rae.es/\%C3\%A9tico (Última consulta: 23 de noviembre de 2020].

72 CORTINA, A., y MARTÍNEZ NAVARRO, E.,Ética (Madrid 2001) 22.

${ }^{73}$ WOLF, U., Ética de la relación entre humanos y animales (Madrid 2014) 27.

${ }^{74}$ SAVATER, F., Tauroética, 54.
}

112 Derecho Animal. Forum of Animal Law Studies, vol. 12/2 
animales no humanos, con seres que padecen. De otro lado, la crítica burlona de disneificar los derechos de los animales, que afirma Savater, asume una tesis que concibe como única justificación de los derechos un punto de vista antropomórfico, sin percatarse de un derecho basado en los intereses propios de las distintas especies animales; los cuales algunos son compartidos y otros no. Como diría Javier de Lucas, la crítica que sostiene el autor donostiarra «supone una confusión sobre la condición misma de los animales, pues [...] es inconcebible salvo a costa de que les atribuyamos características humanas de las que carecen. [En definitiva,] lo que constituye un prejuicio es la separación absoluta, y no al revés» ${ }^{75}$. Cabe recordar que ningún autor de referencia sobre la cuestión animal ofrece un enfoque antropomórfico de la ética animal. Muy al contrario, las diferentes tesis debaten sobre el alcance particular y coherente de los intereses propios de distintas especies.

Por otra parte, la sensibilidad forma parte de la moral y, en esta línea, de la ética. Muchos criterios subjetivos e intersubjetivos se originan a partir de una cierta sensibilidad respecto a una situación con un otro. Es una de las motivaciones de la moral y la ética. Como apunta Ursula Wolf, «si ha de hacerse comprensible cómo los individuos pueden apropiarse normas morales como parte de la orientación personal de su vida, ha de añadirse una motivación positiva mediante afectos al estilo de la compasión, el amor o el cuidado» ${ }^{76}$. En otras palabras, la sensibilidad en sí no es una buena razón, pero a través de un encauzamiento reflexivo y racional puede tornarse en un buen argumento filosófico. De hecho, una falta de motivación compasiva o generosa suele desencadenar en acciones perjudiciales para ese otro. De modo que se intenta justificar la fiesta de los toros en base a valores relativos a la belleza, la estética, la valentía, la caballerosidad y una suerte de honor muy particular ${ }^{77}$. Valores que distan bastante de una ética de las virtudes para la buena vida. Como bien apunta Alicia Puleo, «Para disfrutar de la corrida como torero/a, es preciso controlar el miedo; como espectador/a, se necesita desconectar de la compasión, proceso facilitado aquí por el temor y el desprecio al Otro»» ${ }^{78}$.

En otro orden de cosas, proponer una ética que amplíe nuestra consideración moral hacia otras especies y ser coherentes conforme a esos principios no es una postura arrogante. No hay exceso de magnificencia o de superioridad moral, sino un enfoque crítico que pretende abolir todas las manifestaciones contrarias al maltrato animal y al sufrimiento gratuito o trivializado. Y dado que la ética tiende a lo universal, a pesar de sus matices, es lógico pensar que la ética animal intente cambiar conductas que atenten contra sus principios más básicos. Al igual que los derechos humanos, la ética animal intenta proponer una serie de pretensiones justificadas y, por consiguiente, evitar actos injustos conforme a sus propios valores. Como señala Mosterín, por muy liberal que se considere uno, hay límites que no se pueden sobrepasar cuando causan el embotamiento de la sensibilidad: «Soy partidario de la máxima libertad, en todas las interacciones voluntarias $[\ldots]$ entre ciudadanos. Soy contrario a todo prohibicionismo, excepto en los casos extremos [...]. Pero es que las corridas de toros son un caso extremo ${ }^{79}$. Ciertamente, la libertad es uno de los argumentos propuestos por los partidarios de la tauromaquia. «La asistencia [asevera Fernando Savater] a las corridas de toros es voluntaria y el aprecio que merecen, optativo según cada cual» ${ }^{80}$. Y Wolff añade que «si un día la fiesta de los toros muere por sí misma, será porque ya no desata ninguna pasión. Hasta ese momento, lo prudente es dejar a los unos y a los otros su pasión y hacer prevalecer el principio de libertad» ${ }^{81}$. Jesús Mosterín contestaría que este argumento se basa «en la incomprensión del concepto y en la ausencia de cultura liberal. La libertad que han propugnado los pensadores liberales es la de las transacciones voluntarias entre seres humanos adultos [mientras] no se agreda a terceros ${ }^{82}$. Cabe recordar, en este punto, la célebre idea del liberalismo formulada por John Stuart Mill, pues «la única libertad que merece este nombre es la de buscar nuestro propio bien, por nuestro camino propio, en tanto no privemos a los demás del suyo» ${ }^{83}$. Claro está que los protaurinos no consideran que los toros tengan su propio bien. He aquí el tema central. Pues no se trata de convenir que los animales tienen un bien idéntico al humano, lo cual es discutible, sino reconocer que poseen un bien incuestionable: su vida, en base a la consciencia sobre la misma. Este sería el comienzo para considerar moralmente relevante su sufrimiento. Por tanto, la libertad humana debería cuestionarse cuando su ejercicio implique un daño a un animal, pero en ningún caso podría sostenerse que es indiferente o que ese animal no deba ser considerado ni siquiera de forma mínima. Parece razonable pensar que si la libertad pone en juego la vida y el bienestar de un animal, el interés en juego no debe ser trivial, sino necesario y sumamente importante. Así las cosas, el divertimento y los sentimientos de carácter místico no parecen suficientes para atenuar, en los términos indicados, la vida y el bienestar del toro. En pocas palabras, parece que la clásica afirmación liberal también puede aplicarse a este caso sin sostener una postura animalista.

La libertad, al igual que todos los derechos ${ }^{84}$, no tiene un valor absoluto. Sus límites pueden venir dados por los derechos o intereses de otros individuos, por el orden público o por la moral pública del momento. Es entonces pertinente traer a colación los siguientes datos. En 2019, la asistencia en España a algún espectáculo taurino se encuentra en un $8 \%$ de la población, un $15 \%$ menos que en 2015 , y las corridas celebradas se han desplomado un $50 \%$ en una década ${ }^{85}$. Desde

\footnotetext{
${ }^{75}$ DE LUCAS, J., Bicentenario de Darwin ¿Derechos de los animales no humanos? La barrera de la dignidad, 15.

${ }^{76}$ WOLF, U., Ética de la relación entre humanos y animales, 21.

${ }^{77}$ WOLFF. F, 50 razones para defender la corrida de toros, 69.

${ }^{78}$ PULEO, A., Ecofeminismo para otro mundo posible, 389.

${ }^{79}$ MOSTERÍN, J., A favor de los toros, 74.

${ }^{80}$ SAVATER, F., Tauroética, 75.

${ }^{81}$ WOLFF, F., 50 razones para defender la corrida de toros, 87.

${ }^{82}$ MOSTERÍN, J., A favor de los toros, 79.

${ }^{83}$ STUART MILL, J., Sobre la libertad (Madrid 1970) 69.

${ }^{84}$ Con la única excepción de la prohibición de la tortura o tratos degradantes

${ }^{85}$ REJÓN, R., Los toros pierden medio millón de asistentes en los últimos cuatro años, en El Diario, 1 de octubre de 2019. Según la encuesta de hábitos y prácticas culturales del Ministerio de Cultura. Página Web: https:/www.eldiario.es/sociedad/toros-pierden-
} 
2007 los festejos taurinos han caído un $61 \%{ }^{86}$. Un país donde el $84 \%$ de los jóvenes menores de 24 años se avergüenza de vivir en un país donde se celebran corridas de $\operatorname{toros}^{87}$ y donde solo el 18,6\% de la población está a favor de este espectáculo $^{88}$. En otras palabras, la idea de fondo es que la libertad es un derecho no absoluto que puede verse limitado también por la moral imperante de una sociedad democrática.

Una vez admitido el sufrimiento que padece el toro, otro de los asuntos morales que tratan los protaurinos es una suerte de argumentación de las prioridades. Como es sabido, las muertes animales producidas por la industria cárnica ${ }^{89}$ no son comparables en términos cuantitativos con los festejos taurinos. El argumento tiende a relegar a un segundo plano las consecuencias de la tauromaquia, ya que «mientras que no se afronte el caso de las granjas avícolas y los matadores municipales, el cañonazo de la buena conciencia contra la línea de flotación la fiesta taurina sigue siendo de fogueo», así pues «Si lo que nos preocupa es el sufrimiento de los animales, el verdadero problema está en los millones y millones que criamos para comernos y llevamos al matadero, no en los cientos de toros inmolados en las plazas» ${ }^{90}$. Como si la incorrección o la inmoralidad de un acto se aminorase por ser de menor entidad que otras atrocidades. Es también, por tanto, una apelación al falso dilema. Pues no hay impedimento de oponerse a todo tipo de injusticias. Tal lógica llevaría a afirmar que primero habría que ocuparse de la pobreza antes que de las cuestiones de igualdad de género. Es obvio que en política se establecen ciertas prioridades en base a una ideología determinada, pero desde un punto de vista ético no puede recurrirse a estas prioridades para justificar la total irrelevancia de un hecho inmoral.

Conviene retomar el argumento de la tradición para conectarlo al de la diversidad cultural. Por un lado, se ha expuesto la tauromaquia como costumbre propia de ciertas zonas geográficas, pero, por otro, hay autores que destacan también una idea religiosa o ritual sobre la muerte del toro, de lo animal. Francis Wolff lo expresa así: «Cualquier forma de ritualización ha desaparecido prácticamente de nuestras vidas en los últimos treinta años, sobre todo las ligadas a la muerte: no hay cortejos fúnebres en las ciudades $\gg{ }^{91}$. Es un ritual que muestra la dimensión de la realidad, lo trágico de la herida y la muerte; un ritual que nos afirma «esta verdad: sí, es innegable, morimos» ${ }^{92}$. De otro lado, desde una interpretación materialista, según Alfonso Fernández Tresguerres, se debería

reconocer la existencia de un vínculo de religiosidad real (objetiva) entre el hombre y el toro, que se encuentra en el origen y la base de la corrida española, la cual ha de ser vista, por tanto, como una renuncia de antiguas formas de religiosidad primaria [el culto] y secundaria [el sacrificio], que perviven (como juego) en el seno de las religiones terciarias, pero cuya comprensión esencial es imposible a menos que se reconozca de modo expreso su origen y carácter religioso. ${ }^{93}$

En base a estas cuestiones, la tauromaquia debería representar una variedad cultural más, la cual debe ser respetada por formar parte del pluralismo cultural y en tanto que no viola ningún derecho humano. Y como los principios universales de igualdad y dignidad no son aplicables a los animales, la tauromaquia enriquecería la diversidad cultural. La objeción en este punto es similar a la dada para el argumento de la tradición. Ni toda tradición es correcta ni toda diversidad es positiva per se. Los individuos deben ser el centro de la consideración moral y no la pluralidad de expresiones culturales. La diversidad en sí no es estrictamente un valor moral. Véase la pluralidad de objetos, de colores, de elecciones consumistas e, incluso, de especies animales. La implicación moral de la diversidad deriva del objeto de la misma. Así es, la cultura es lo que ofrece esa importancia. Lo cultural es moral, pero no la diversidad como concepto. Es más, en muchas ocasiones, se realiza una lectura puramente estética de la diversidad, que si bien puede habilitar ciertas sensibilidades o morales, no es en sí misma una cuestión ética. Ahora bien, la homogeneidad en las formas de entender el mundo no parece ser una opción positiva ni viable respecto a la libertad y la etología humana; pues la diversidad cultural y el intercambio forman un dispositivo (y un disparador) del desarrollo individual y social. Un estadio dinámico que evita el discurso único, por bueno y virtuoso que sea. En todo caso, lo relevante moralmente es la libertad que entraña la diversidad. Lo positivo sería la no limitación de expresiones que no dañen a otros. Lo deseable sería que las diferentes

medio-millon-asistentes_1_1335222.html [Última consulta: 25 de noviembre de 2020].

${ }^{86}$ CERILLO, A., La epidemia da la estocada a los toros, en La Vanguardia, 3 de junio de 2020. Según Estadísticas de Asuntos Taurinos del Ministerio de Cultura. Página web: https://www.lavanguardia.com/cultura/20200703/482055792657/la-epidemia-da-la-estocadatoros-banuelos-el-fundi.html [Última consulta: 25 de noviembre de 2020].

${ }^{87}$ INFOLIBRE, El 84\% de los jóvenes de 16 a 24 años se avergüenza de vivir en un país con toros, 21 de enero de 2016. Según la encuesta de Ipsos Mori. Página Web:

https://www.infolibre.es/noticias/politica/2016/01/21/el_los_jovenes_24_anos_esta_quot_poco_quot_quot_nada_quot_orgulloso_vi vir_pais_con_toros_43668_1012.html [Última consulta: 25 de noviembre de 2020].

${ }^{88}$ EL PLURAL, Encuesta: Casi la mitad de los españoles, a favor de prohibir los toros, 6 de mayo de 2020. Según datos de Electomanía. Página Web: https://www.elplural.com/sociedad/encuesta-mitad-espanoles-favor-prohibir-toros_239267102 [Última consulta: 25 de noviembre de 2020].

${ }^{89}$ Solo en España se mató a más de 900 millones de vertebrados terrestres en 2019. Entre ellos: 53 millones de cerdos, 823 millones de aves o 2 millones y medio bovinos. Fuente: Gobierno de España. Página Web:

https://www.mapa.gob.es/es/estadistica/temas/estadisticas-agrarias/ganaderia/encuestas-sacrificio-ganado/ [Última consulta: 25 de noviembre de 2020].

90 SAVATER, F., Tauroética, 69.

${ }^{91}$ WOLFF, F., 50 razones para defender la corrida de toros, 55.

${ }^{92}$ Idem. 74

${ }^{93}$ FERNÁNDEZ TRESGUERRES, A., La corrida de toros como ceremonia angular: una interpretación materialista, en Revista de Estudios Taurinos, 12 (2000) 85-86. En https://idus.us.es/handle/11441/79522 [Última consulta: 20 de noviembre de 2020]. 
culturas pudieran convivir entre ellas siempre que no traspasen unos límites mínimos, de ética mínima ${ }^{94}$. Uno de estos límites sería la utilización trivial y banal de la violencia y la banalización del sufrimiento. Otro sería la perpetuación de una cultura de la violencia y la opresión. En este sentido, no todo límite del pluralismo cultural se remite a actos entre seres humanos, pues, como se ha dicho, las cuestiones éticas van más allá de estas fronteras. Y, sin embargo, el artículo 13 del Tratado de Funcionamiento de la Unión Europea recoge que

la Unión y los Estados miembros tendrán plenamente en cuenta las exigencias en materia de bienestar de los animales como seres sensibles, respetando al mismo tiempo las disposiciones legales o administrativas y las costumbres de los Estados miembros relativas, en particular, a ritos religiosos, tradiciones culturales y patrimonio regional.

Del mismo modo, varios ordenamientos jurídicos, entre ellos el español, despenalizan y legalizan el maltrato animal por razones ancladas en la tradición o por previsión legal lo que habilite. Es, por ende, palpable la incoherencia de la regulación. Únicamente defendible desde un enfoque antropocéntrico fuerte. De este modo, se pueden imponer penas de privación de libertad por el maltrato a un perro y que esa misma acción a un toro quede amparada por el ordenamiento jurídico. Animales, recordemos, que poseen la misma capacidad para sentir dolor y placer, la misma capacidad para tener experiencias subjetivas y una complejidad etológica similar. Ello debido al similar sistema límbico del cerebro que poseen.

Volviendo al pluralismo cultural, ciertamente nada valioso se perdería de la cultura española si se eliminasen las prácticas crueles y sangrientas. Nada perdería el resto de comunidades de no poder incorporar valores taurinos a sus propias culturas. Al revés, se contribuiría a un pluralismo cultural conforme a los valores de la empatía y la compasión, los valores que propugnan la convivencia respetuosa entre los humanos y las distintas especies animales que comparten con nosotros este planeta. Parafraseando a Marta Vericat, a través del respeto a todos los seres considerados moralmente «podremos avanzar cualitativamente como personas» ${ }^{95}$, como sociedades cuyos valores sean dignos de compartir, de ser aprendidos y aprehendidos. Y así, podrían afirmarse las diferentes concepciones de una vida buena, donde el respeto a la vida y el principio de violación mínima de los intereses ajenos sean dos ejes esenciales y transversales.

\subsection{Conclusiones}

Una postura antropocéntrica fuerte defiende que el sufrimiento de los animales no es relevante en cuestiones éticas. De un lado, porque lo animal no forma parte del núcleo de este campo. De otro, porque la sensibilidad respecto al dolor de los no humanos es una posición subjetiva que no puede ni debe ser impuesta. Así pues, las tradiciones que no violen los derechos humanos deben ser respetadas a razón de la libertad y la diversidad cultural.

Desde un enfoque bienestarista se han sostenido razones para abolir la tauromaquia en cualquiera de sus formas. La crueldad animal no debería constituir parte de la cultura de una sociedad que aspire a una ética de las virtudes de la compasión, la empatía y la solidaridad. En esta línea, aunque no se reconozca que los animales poseen derechos, cabe admitir que tienen un importante valor moral en base a su capacidad de experimentar subjetivamente. Y, por tanto, los actos individuales y las políticas públicas deben considerar los intereses propios de estos. No bastan las razones triviales, estéticas o innecesarias para menoscabar estos intereses (ya sea su vida o su integridad). Es más, de hacerlo debería realizarse mediante el menor sufrimiento posible. Afirmación que no es compatible con los espectáculos taurinos. Ni la tradición ni la diversidad cultural por sí mismas son buenas razones para permitir el sufrimiento de seres sensibles.

Por otro lado, bajo el prisma de la teoría de los derechos de los animales es inadmisible este tipo de actos. En tanto que los toros serían sujetos de derecho y poseerían derechos básicos como el derecho a la vida y a no ser sometidos a tratos crueles o degradantes, la tauromaquia sería una práctica contraria a los intereses más básicos de estos titulares de derechos. Al igual que ocurre con los derechos humanos, los límites de la diversidad cultural serían claros en este supuesto. No basta la remisión al argumento de la diversidad de las tradiciones para justificar una violación de los derechos esenciales de todo ser sintiente. La ponderación de los intereses en juego sería ridícula: por un lado, los citados derechos básicos de los animales no humanos y, de otro, el interés de satisfacer una suerte de ocio cruel. Diversión que no quedaría amparada por el derecho a la libertad, pues este derecho también encuentra sus límites en el daño a terceros. Máxime cuando se defiende a partir de un motivo trivial. De otro lado, hay que tener en cuenta que el sujeto pasivo no tiene la capacidad de consentir o, en una interpretación amplia del consentimiento, este estaría viciado por su contexto.

Debería añadirse, además, que parece pertinente analizar críticamente nuestra propia cultura para poder legitimar una proposición crítica respecto a otras culturas. Desde luego sería incoherente y etnocéntrico defender la tauromaquia por formar parte de una tradición española y criticar al mismo tiempo otro tipo de costumbres similares que se dan en otras comunidades humanas. De igual modo, tolerar acríticamente todo reflejo de la cultura nos adentra en el relativismo moral y no sería esta una opción conveniente, dado que las estructuras sociales suelen oprimir a los más débiles. En este caso, a los animales no humanos.

\section{Los animales y la religión: la carne kosher y halal}

\footnotetext{
${ }^{94}$ Obviamente, el contenido de esta ética mínima difiere de la expresada en CORTINA, A., Ética mínima. Basta recalcar que, en una ética de mínimos animalista, los animales sintientes serían sujetos moralmente relevantes, con unos derechos básicos que respetar. ${ }^{95}$ VERICAT. M., Filosofía y toros, 161.
} 
Las tres grandes religiones monoteístas abordan con mayor o menor intensidad la cuestión de la alimentación de origen animal. Este apartado se centrará en los ritos judíos e islámicos de la matanza de animales para su consumo. Estos ritos se han puesto en entredicho en varios países de Europa: Eslovenia, Dinamarca, Suecia o Bélgica han adoptado una serie de regulaciones para impedir o limitar el sufrimiento animal que conllevan estos rituales. La controversia gira en torno al bienestar animal que propugnan los países miembros de la Unión Europea.

Halal significa lícito, lo permitido. Lo prohibido se denomina haram. «Fuera del mundo islámico, el término se conoce sobre todo asociado a la alimentación» ${ }^{96}$, pero lo cierto es que el concepto de halal se extiende a todos los apartados de la vida. En términos generales, se refiere a «permitir lo que había sido vedado, librarse de un pacto o de una prohibición. Puede tratarse de alimentos, acciones, relaciones o conductas» ${ }^{97}$. En el Corán (5: 4) se indica que

Se os prohíbe la carne de un animal que muera por sí mismo y la sangre y la carne del cerdo; la de los sacrificados invocando un nombre distinto del de Al-lah; la del que ha sido estrangulado, la del que ha sido golpeado hasta la muerte; la del que ha muerto a causa de una caída y del corneado hasta la muerte; la del que ha sido parcialmente devorado por una fiera, salvo que lo hayáis sacrificado adecuadamente; y los animales sacrificados en un altar. ${ }^{98}$

Según el texto sagrado, se prohíbe tanto la carne de cerdo como la de cualquier animal que no haya sido desangrado previamente mediante el ritual de la dabiha.

Para el judaísmo la palabra que corresponde a lo permitido ritualmente es kosher. Para que un alimento sea permitido debe seguirse las leyes del kashrut, por las cuales se purifican los alimentos prohibidos. Los alimentos no aptos se denominan terefá. En el Talmud se recogen las leyes dietéticas, en concreto en la sección Yoré Deá de Slján Aruj del tratado de Julín ${ }^{99}$. La Torá permite el consumo de ciertos animales mediante el shechita, como así se menciona en el Levítico. En concreto, dado que

la sangre de animales cuadrúpedos y de aves no se puede consumir "Cuida mucho de no consumir la sangre" (Deuteronomio Cap. 12-23), [de modo que] la ley judía nos ordena el degüello ritual, con un cuchillo muy afilado y sin mella alguna: Se degüella la tráquea y el esófago de una vez, para que el animal se desangre rápidamente y así pierde el conocimiento enseguida sin sentir dolor. ${ }^{100}$

Se observa, por ende, una estrecha similitud entre ambos rituales, incluida la prohibición de la carne de cerdo. Existen varias tesis para explicar la prohibición de la carne de cerdo y la sangre del resto de animales no aptos, tales como la salubridad o razones ecológicas de aquella época, pero no hay que olvidar que los tabúes también cumplen «funciones sociales, como ayudar a la gente de considerarse una comunidad distinta» ${ }^{101}$, tan importante respecto a la necesidad del individuo de pertenecer a un grupo concreto. Sea como fuere, las carnes kosher y halal son una seña de identidad religiosa y forman parte del entramado cultural de todos los creyentes de ambos credos. A continuación se abordarán estos ritos desde diferentes argumentos a colación de la vida animal y las consecuencias que desembocan en el plano del pluralismo cultural.

\subsection{El argumento de la libertad religiosa}

La libertad religiosa ostenta diferentes ámbitos de la libertad y la autonomía del individuo. La realización de prácticas religiosas puede contravenir ciertos aspectos de la moral pública. Es entonces cuando surge un conflicto de intereses, en este caso, si lo comparamos con los estándares establecidos por la Unión Europea respecto al bienestar animal. El Convenio Europeo de Protección de los Animales en Explotaciones Ganaderas ${ }^{102}$ es un claro ejemplo. Mayor relevancia ostenta el artículo 3 de la Directiva 98/58/CE, donde se expone que «Los Estados miembros adoptarán las disposiciones necesarias para que el propietario o criador tome todas las medidas adecuadas para asegurar el bienestar de los animales con vistas a garantizar que dichos animales no padezcan dolores, sufrimientos ni daños inútiles» ${ }^{103}$. En este orden de cosas, el Reglamento $n^{\circ} 1099 / 2009$ del Consejo ${ }^{104}$, relativo a la protección de los animales en el momento de la matanza, establece en su artículo 2 que los Estados «deben adoptar las medidas necesarias para evitar el dolor y reducir al mínimo la angustia y el sufrimiento de los animales durante los procesos de sacrificio o matanza», mientras

\footnotetext{
${ }^{96}$ GÓMEZ GARCÍA, L., Diccionario de islam e islamismo (Madrid 2009) 130.

97 MONTURIOL, Y., Términos clave del islam (Córdoba 2006) 34.

98 Léase: Corán, Al-Maidah 5:4. Página Web: https://www.ahmadiyya-islam.org/es/coran/capitulos/5/ [Última consulta: 1 de diciembre de 2020].

${ }^{99}$ COHN-SHERBOK, D., Breve enciclopedia del judaísmo (Madrid 2003) 134.

100 ASERIN FARACHE, C., Las leyes dietéticas del judáismo. Una dieta para el alama, Aldaba. 36 (2013) 99. https://doi.org/10.5944/aldaba.36.2012.20533 [Última consulta: 1 de diciembre de 2020].

${ }^{101}$ HARRIS, M., Vacas, cerdos, guerras y brujas, 48.

${ }^{102}$ Convenio Europeo de Protección de los Animales en Explotaciones Ganaderas del Consejo de Europa. Página Web: https://eurlex.europa.eu/legal-content/ES/TXT/?uri=celex\%3A21978A1117\%2801\%29 [Última consulta: 2 de diciembre de 2020].

${ }_{103}$ Directiva 98/58/CE del Consejo de 20 de julio de 1998 relativa a la protección de los animales en las explotaciones ganaderas. Página Web: https://eur-lex.europa.eu/legal-content/ES/TXT/?uri=CELEX:31998L0058 [Última consulta: 2 de diciembre de 2020].

${ }^{104}$ Reglamento $n^{\circ} 1099 / 2009$ del Consejo de 24 de septiembre de 2009, relativo a la protección de los animales en el momento de la matanza. Página Web: https://eur-lex.europa.eu/legal-content/ES/TXT/HTML/?uri=CELEX:32009R1099\&from=EN [Última consulta: 2 de diciembre de 2020].
} 
que su artículo 4 menciona que «El bienestar de los animales es un valor comunitario consagrado en el Protocolo $\mathrm{n}^{\circ} 33$ sobre la protección y el bienestar de los animales anejo al Tratado constitutivo de la Comunidad Europea». Sin embargo, en los artículos 15 y 16 excluyen del ámbito de aplicación del Reglamento las tradiciones culturales y costumbres de los Estado, en particular, los ritos religiosos. En la normativa europea no encontramos, pues, un principio absoluto en aras del bienestar animal, ni siquiera en el artículo 13 del Tratado Funcionamiento de la Unión Europea ${ }^{105}$, que declara a los animales no humanos como seres sensibles o sintientes. Más bien lo contrario, este valor puede ceder, por ejemplo, ante las celebraciones religiosas. En esta línea, cabe destacar la sentencia del Tribunal de Justicia de la Unión Europea, de 19 de mayo de 2018, en el caso de la Liga van Moskeeën en Islamitische Organisaties Provincie Antwerpen, VZW y otros contra Vlaams Gewest ${ }^{106}$. El asunto versaba sobre unos mataderos temporales a razón de las festividades islámicas. En relación con nuestro propósito es necesario señalar que el tribunal entiende que los sacrificios de los animales en cuestión sin aturdimiento previo se encuentran dentro del concepto de «rito religioso», y como actos de cultos (párrafos 48 y 49) amparados por el artículo 10 de la Carta de los Derechos Fundamentales de la Unión Europea. En los párrafos 56 y 57 de la sentencia se recalca la excepción autorizada del citado Reglamento n 1099/2009, en cuyo texto

no establece ninguna prohibición de la práctica del sacrificio ritual en la Unión, sino que, por el contrario, manifiesta el compromiso positivo del legislador de la Unión de permitir la práctica del sacrificio de animales sin aturdimiento previo a fin de garantizar el respeto efectivo de la libertad de religión, en particular de las prácticas musulmanas, durante la Fiesta del Sacrificio.

En el siguiente párrafo reitera que es clara la enunciación de la excepción respecto a la obligación de aturdimiento de los animales antes del sacrificio precisamente con el fin de garantizar el respeto de la libertad de religión y el derecho a manifestar la religión o las convicciones a través de las prácticas y la observancia de los ritos, de acuerdo con el artículo 10 de la Carta.

El fondo del asunto trata sobre los sobrecostes de crear nuevos mataderos conforme a derecho para la práctica de estos rituales. Sin embargo, esto no añade nada respecto al asunto de este trabajo. En conclusión, la Unión ampara los rituales dabiha y shechita en aras de la libertad religiosa y en detrimento del bienestar animal. El mencionado Reglamento no opera y no puede operar como un límite de la libertad religiosa consagrada en la Carta.

Efectivamente, la cuestión religiosa ha sido una de las causas de discriminación histórica, por lo que las legislaciones de muchos países han formulado de forma cuidadosa el derecho de la libertad religiosa. Además, la fe religiosa es un elemento esencial en la identidad de las personas creyentes, por eso, algunos «argumentos religiosos asumen que las actividades religiosas no pueden tratarse igual a otras actividades humanas, sino que deben recibir especial protección» ${ }^{107}$.

Las medidas que limitan la práctica de estos rituales son vistas como una amenaza para la identidad religiosa. El presidente de la Europe Jewish Association, Rabbu Menachem, afirmó que «esto pone una sombra en nuestra comunidad y las leyes judías, esencialmente se dice que no confían en nuestro bienestar con los animales, que necesita de una supervisión gubernamental. Esto es un precedente terrible para asentarse en un nivel internacional» ${ }^{108}$. Es más, se argumenta que los rituales deben realizarse bajo una formación donde «es imprescindible demostrar los conocimientos en anatomía y patología animal y un periodo de aprendizaje junto con un Sohet consumado [la persona habilitada para la matanza], a modo de instructor en la pericia que requiere este tipo de actividad» ${ }^{109}$. Y que, por tanto, el animal no sufre tanto como se suele afirmar. En base a esta idea, el rabino Genack cree que muchas de las prohibiciones o limitaciones respecto a las religiones provienen de un sentimiento anti-semita y anti-musulmán en Europa ${ }^{110}$.

A esta postura se le puede objetar que las cuestiones religiosas deben tener una serie de limites respecto a la moral pública $^{111}$. Como ya se ha expuesto, el artículo 13 del TFUE expone que el bienestar animal debe ser incorporado por

\footnotetext{
105 «Al formular y aplicar las políticas de la Unión en materia de agricultura, pesca, transporte, mercado interior, investigación y desarrollo tecnológico y espacio, la Unión y los Estados miembros tendrán plenamente en cuenta las exigencias en materia de bienestar de los animales como seres sensibles, respetando al mismo tiempo las disposiciones legales o administrativas y las costumbres de los Estados miembros relativas, en particular, a ritos religiosos, tradiciones culturales y patrimonio regional», en https://www.boe.es/doue/2010/083/Z00047-00199.pdf [Última consulta: 10 de enero de 2021].

${ }^{106}$ Sentencia del Tribunal de Justicia de la Unión Europea, de 19 de mayo de 2018, en

http://curia.europa.eu/juris/document/document.jsf;jsessionid=1FC143A8A584D4DB7C0DE48F7D7D5FF2?text=\&docid=202301

\&pageIndex $=0 \&$ doclang=ES\&mode=1st\&dir=\&occ=first\&part=1\&cid=15978186 [Última consulta: 2 de diciembre de 2020].

${ }^{107}$ CASAL, P., Cultura y crueldad, en Animales no humanos entre animales humanos (Madrid 2012) 51.

108 Traducción propia de GARAEV, P., Ban on ritual slaughtee causes Belgium's Jews to import meat form Hungary, en i24news, de 2 de junio de 2019. Página Web: https://www.i24news.tv/en/news/international/europe/192316-190102-ban-on-ritual-slaughtercauses-belgium-s-jews-to-import-meat-from-hungary [Última consulta: 2 de diciembre de 2020].

${ }^{109}$ VALENCIA CANDALIJA, R., Sacrificio ritual y alimentación kosher: referencia a las novedades legislativas sobre la sechita en Bélgica, en Anuario de Derecho Eclesiástico del Estado de la Universidad de Sevilla, XXXV (2019): 388, en https://www.boe.es/biblioteca_juridica/anuarios_derecho/abrir_pdf.php?id=ANU-E-2019-

10037700416_ANUARIO_DE_DERECHO_ECLESI\%C3\%81STICO_Sacrificio_ritual_y_alimentaci\%C3\%B3n_Kosher:_referenci a_especial_a_las_novedades_legislativas_sobre_la_Shechita_en_B\%C3\%A9 [Última consulta: 2 de diciembre de 2020].

${ }_{110}$ ZRAICK, K., Is Stunning an Animal Before Slaughter More Humane? Some Religious Leaders Say No, en The New York Times, 9 de enero 2019. Página Web: https://www.nytimes.com/2019/01/09/world/europe/halal-kosher-humane-slaughter.html [Última consulta: 1 de diciembre de 2020].

${ }^{111}$ Véase, por ejemplo, que el artículo 16.1 de la Constitución española de 1978 recoge que «Se garantiza la libertad ideológica, religiosa y de culto de los individuos y las comunidades sin más limitación, en sus manifestaciones, que la necesaria para el
} 
las legislaciones de los Estados miembros. Ello conlleva una moral que tiende a causar el menor daño posible a los animales. Sirva de ejemplo una encuesta publicada en el diario The Guardian, donde se muestra que nueve de cada diez ciudadanos de la Unión se oponen a la muerte del animal sin aturdimiento previo ${ }^{112}$. La mayoría de los encuestados demandan medidas estrictas para evitar el sufrimiento de los animales. Si se establecen las excepciones a esta prohibición se debe a que no se toma en serio el intereses de no sufrir del animal sintiente. Es decir, los ordenamientos jurídicos vigentes descansan en el antropocentrismo y, por tanto, el conflicto entre un derecho fundamental y el bienestar animal, como bien jurídico, es apenas discutible. Ahora bien, como reflexiona adecuadamente Ursula Wolf, a pesar de que los animales no ostenten derechos fundamentales, «desde que la protección de animales en Alemania y Suiza está amparada por el derecho constitucional, ¿no tendría el Estado que interpretar con más fuerza la protección de los animales e imponerla con mayor amplitud $[\ldots] ?{ }^{113}$.

En todo caso, hoy en día no parece aplicable los límites de la moral pública a estas situaciones. Pues, de lo contrario, ninguna práctica religiosa que atentase contra el bienestar animal obtendría amparo legal. He aquí una importante puntualización: este tipo de excepción solo procede ante religiones autorizadas o regularizadas, al menos en el caso español. Los ritos de santería, en cambio, no se encuentran amparados por las legislaciones. Por tanto, no se trata tanto del hecho en sí, sino de su contexto. Esta objeción parte de negar un derecho cultural a la crueldad, pues, como sostiene Paula Casal, esto

no implica negar una consideración especial a las minorías culturales. Tenemos muchas razones igualitarias para mejorar la situación de las minorías y avanzar hacia un mundo más justo en el que pertenecer a las mismas no sea una desventaja. Hay también razones basadas en el valor de la diversidad, como bien en sí, como bien colectivo y como oportunidad para observar con más sentido crítico y perspectiva lo que uno hace por costumbre. ${ }^{114}$

En coherencia con la objeción hay que afirmar que toda la industria cárnica intensiva conlleva un alto sufrimiento de todos los animales que son utilizados directa o indirectamente para alimento ${ }^{115}$. Uno de los casos más evidentes es el del foie gras. Es más, una de las razones del aumento de los estándares de bienestar animal viene dado por la productividad que lleva aparejada. Varios estudios han mostrado que mejorar la calidad de vida de los animales en granjas ofrece un mejor producto ${ }^{116}$. En definitiva, la crítica bienestarista debería estar generalizada respecto a toda práctica que atente contra el bienestar animal y no solo (ni especialmente) frente a los rituales religiosos.

A pesar de todo lo descrito, lo cierto es que en una reciente resolución del Tribunal de Justicia de la Unión Europea $^{117}$, de 17 de diciembre de 2020, se toma en serio la consideración de «la creciente sensibilización» de la ciudadanía respecto a la cuestión del sufrimiento animal. En aras de compatibilizar el bienestar animal y la libertad religiosa, el Tribunal de Justicia, previa consulta del Tribunal Constitucional belga a raíz de la mencionada prohibición de estos rituales, afirma que el Estado puede prohibir este tipo de prácticas ya que las medidas adoptadas por el gobierno belga «permiten garantizar un justo equilibrio entre la importancia concedida al bienestar animal y la libertad de los creyentes judíos y musulmanes de manifestar su religión y, por consiguiente, son proporcionadas», ajustadas así a los criterios de adecuación y proporcionalidad. El Tribunal añade que el hecho de que las autoridades belgas hayan prohibido estos rituales pero no la caza o la pesca (comportando un sufrimiento similar) no es contrario a los principios de igualdad, no discriminación y diversidad cultural y religiosa; pues sus efectos son marginales en comparación con las actividades de la producción de carne y, además, estos animales no son suceptibles de aturdimiento previo.

La resolución del Tribunal de Justicia no parece aportar buenos argumentos en relación con el trato desigual de una actividad y otra, pues la condición cuantitativa no altera la cualitativa de los hechos. Si bien el Tribunal se basa en la interpretación de la realidad social de la legislación europea, no parece que esta sea aplicada de forma imparcial en todos los casos, ni suficientemente justificada la proporcionalidad de la prohibición en términos antropocéntricos. Tampoco se justifica de forma suficiente la ponderación de los intereses en conflicto: bienestar animal y libertad religiosa. En definitiva, aunque la resolución sea positiva para los intereses de los animales no amplía tal protección a cualquier actividad de matanza animal, dejando la cuestión de fondo intacta.

\subsection{El argumento de la no necesidad}

En este apartado se van a ofrecer dos enfoques sobre la no necesidad de la práctica de los rituales dabiha y shechita

mantenimiento del orden público protegido por la ley».

${ }^{112}$ KOSC, W., Nine out of 10 EU citizens oppose animal slaughter without stunning, poll finds, en The Guardian, 9 de octubre de 2020. Página Web: https://www.theguardian.com/environment/2020/oct/09/nine-out-of-10-eu-citizens-oppose-animal-slaughterwithout-stunning-poll-finds [Última consulta: 1 de diciembre de 2020].

${ }^{113}$ WOLF, U., Ética de la relación entre humano y animales, 209.

${ }^{114}$ CASAL, P., Cultura y crueldad, 77.

115 Léase algunas de las condiciones en las que viven y mueren los animales destinados a la alimentación en Igualdad Animal,«Problemática». Página Web: https://igualdadanimal.org/problematica/carne/ [Última consulta: 5 de diciembre de 2020].

116 PÉREZ BENAVENTE, R., Bienestar animal en las granjas: no sólo es una cuestión ética, sino también económica, en Público, 4 de septiembre de 2019. Página Web: https://www.publico.es/sociedad/granjas-animales.html [Última consulta: 5 de diciembre de 2020].

${ }^{117}$ Sentencia de 17 de diciembre de 2020, sobre el asunto C-336/19, en

http://curia.europa.eu/juris/document/document.jsf;jsessionid=149CBC8612FC08E51F3261F5C4E8F973?text=\&docid=235717\&pa geIndex $=0 \&$ doclang=ES\&mode=req\&dir=\&occ=first\&part=1\&cid=23538518 [Última consulta: 20 de diciembre de 2020].

118 Derecho Animal. Forum of Animal Law Studies, vol. 12/2 
tal y como se han descrito. El primero en relación con la posibilidad de aturdir al animal antes de la muerte. El segundo versará sobre la no necesidad de comer animales según los textos sagrados del judaísmo y del islam.

En realidad, la imposición de no aturdir al animal previamente no es unánime, pues, por ejemplo, «los líderes judíos siguen divididos sobre si el método del aturdimiento es aceptable y sobre cuántos segundos se debe esperar» ${ }^{118}$. Por otra parte, señala Jesús Mosterín, en su libro Islam, que

los partidarios acérrimos de la dabiha consideran que si el animal es aturdido, sedado o muerto antes de ser degollado y desangrado, su cuerpo es automáticamente carroña, algo cuyo consumo está explícitamente prohibido en el Corán», aunque no todo el mundo está de acuerdo con esta interpretación. En cualquier caso, los detalles de la técnica de matanza objeto de la dabiha no provienen del Corán, sino meramente de la tradición. ${ }^{119}$

En un término medio algunos rabinos ortodoxos «permiten el aturdimiento después del corte -una técnica en la que los cuellos de los animales son cortados casi al mismo tiempo que quedan inconscientes. [Otro método sería la aplicación] de dióxido de carbono» ${ }^{120}$ para que el animal no sea consciente del dolor que se le causa.

Así es, como señala Dan Cohn-Sherbok, las leyes alimentarias son un buen ejemplo de la diversidad que existe dentro de las comunidades religiosas. Esta pluralidad de posturas también se observa en la aprobación de ciertas autoridades para la práctica del ritual o, incluso, hay judíos que fuera de casa no comen carne kosher $^{121}$.

Es después del Diluvio que se permitió comer carne con las restricciones correspondientes y el respeto a la dignidad del animal. Por ello,

El judaísmo rechaza el sufrimiento del animal, pues un principio cardinal es el respeto por todas las criaturas y en ese sentido está prohibida también la caza, como un deporte. A diferencia de cualquier otro sistema legal o religioso, la Torá prohíbe degollar en un mismo día un animal adulto y su cría, pues implicaría la desaparición de dos generaciones a la vez y aún cuando los animales no se dan cuenta de ello, el hombre está llamado a no ser cruel. $^{122}$

En el islam, la dabiha también se concibe como la manera menos cruel en el desangramiento necesario del animal. Con los nuevos sistemas mecánicos de aturdimiento parece que la carnicería ritual pueda ser considerada la más cruel, pero «no hay que olvidar que la sacralización del acto de la matanza responde, en su origen a la superación del sentimiento de culpa que comporta la ejecución de cualquier ser vivo» ${ }^{123}$.

Ante lo expuesto, en concordancia con un enfoque bienestarista, no parece que haya impedimento en evitar el sufrimiento de los animales antes de su muerte. La práctica de estos rituales puede modularse para seguir respetando los mandatos sagrados. Más aun cuando la esencia de estos rituales viene dada por el respeto a la vida y no causar un sufrimiento innecesario.

El segundo argumento apunta a un estilo de vida vegetariano o vegano ${ }^{124}$ por parte de los religiosos. Lo que no significa que pueda sostenerse una defensa de los derechos de los animales. La ética vegana (o vegetariana) no es prescriptiva, mientras que una tesis de los derechos de los animales sería normativa. Aclarar que el veganismo «es una filosofía y un modo de vida que busca excluir -en la medida de lo posible y lo practicable- todas las formas de explotación y de crueldad hacia los animales» ${ }^{125}$. El veganismo descansa en un hecho constatado: no es necesario consumir animales ni sus derivados para obtener una nivel de salud adecuado en los humanos ${ }^{126}$.

Las tres grandes religiones monoteístas descansan en valores como la caridad, la compasión y la preocupación

${ }^{118}$ Traducción propia de ZRAICK, K., Is Stunning an Animal Before Slaughter More Humane?..., en The New York Times.

${ }^{119}$ MOSTERÍN, J., El islam. Historia del pensamiento (Madrid 2018) 177.

${ }^{120}$ Traducción propia de LIPHSHIZ, C., Belgian ban on kosher slaughter has Jews worried about what comes next, en Times of Israel, 4 de enero de 2019. Página Web: https://www.timesofisrael.com/belgian-ban-on-kosher-slaughter-has-jews-worried-about-whatcomes-next/ [Última consulta: 5 de diciembre de 2020].

${ }^{121}$ COHN-SHERBOK, D., Judaísmo (Madrid 2001) 84.

${ }^{122}$ LUVAVITCH, J., Vegetarianismo en la perspectiva judía, Tu guía del judaísmo. Página Web:

https://www.tora.org.ar/vegetarianismo-en-la-perspectiva-judia/ [Última consulta: 5 de diciembre de 2020].

${ }^{123}$ BRANCA, P., Los musulmanes (Madrid 2004) 65.

${ }^{124}$ La diferencia más importante entre el veganismo y el vegetarianismo es que esta segunda opción no veta el consumo de alimentos derivados de animales, como la leche o los huevos.

125 Traducción propia de Vegan Society, «Definition of veganism». Página Web: https://www.vegansociety.com/go-vegan/definitionveganism [Última consulta: 5 de diciembre de 2020].

${ }^{126}$ Uno de los temas capitales de la cuestión animal es el de la nutrición, la necesidad o no de alimentarse de animales para conseguir una vida saludable. Pues bien, los avances en nutrición y endocrinología han demostrado (evidencia científica) que llevar una dieta basada exclusivamente en plantas es saludable en todas las fases de la vida, siempre que se complemente con un suplemento vitamínico de B12. Así lo avalan numerosas entidades: la Organización Mundial de la Salud (Naciones Unidas), Asociación Americana de Dietética, The Canadian Dietetic Association o British Medical Association, entre otras de diferentes países. El suplemento de vitamina B12, por otra parte, es económicamente muy accesible y que, además, desde hace décadas se suministra a través del pienso también a la inmensa mayoría de los animales explotados (tanto a la ganadería intensiva y como en parte de la extensiva) que consume la sociedad. De hecho, «El mercado que más cantidad de vitamina B12 demanda es el de producción de alimentación para ganado, especialmente porcino y aviar». Para más información: GÓMEZ MANRIQUE, A., Estudio de viabilidad de instalación de una planta de producción de vitamina B12 en España, en Cuadernos del Tomás, 9 (2017) 109, en

https://dialnet.unirioja.es/descarga/articulo/6245306.pdf [Última consulta: 20 de noviembre de 2020]. 
por el dolor ajeno. No es de extrañar entonces que se pueda practicar una de estas religiosas y, al mismo tiempo, acomodarse a un estilo de vida vegano o vegetariano. Es más, «el vegetarianismo -afirma Cohn-Sherbok- está creciendo en la comunidad judía, ya sea por motivos religiosos o por razones de salud» ${ }^{127}$. Tanto para el islam como para el judaísmo la vida tiene un valor central en su fe. Los mencionados rituales tienen como objetivo transformar lo prohibido en permitido. Como se ha dicho, la permisión del consumo de estas carnes viene a superar el sentimiento de culpa de arrebatar una vida. La crueldad, por ende, estaría prohibida. Como bien indica Carl S. Ehrlich:

Las leyes judías sobre la alimentación (kashrut) son una expresión de la santidad de la vida. Desde el punto de vista judío, debido a que el vegetarianismo es el estado ideal, y el consumo de carne fue una concesión hecha por Dios después del diluvio, no todos los animales pueden ser consumidos. Aquellos que pueden consumirse deben sacrificarse de la manera más rápida e indolora posible, pues una criatura que sufre innecesariamente no es kosher ("adecuado", “apto"). La crueldad hacia los animales viola, en general, las creencias éticas judías básicas, de ahí que el judaísmo prohíba la caza. ${ }^{128}$

En conclusión, no cabe duda que la ética vegana es totalmente compatible con las confesiones religiosas aquí expuestas. Cuestión distinta es la acomodación de una teoría de los derechos de los animales en las legislaciones de países donde gobiernan las correspondientes autoridades religiosas, pues el consumo animal estaría permitido por la autoridad divina aunque la autoridad civil lo prohibiese. Eso sí, parece que una vida sin consumo de carne animal es la opción más coherente con la filosofía que subyace en ambas religiones. Así lo han entendido varios rabinos: Shlomo Riskin o Abraham Isaac Hakohen Kook, entre otros muchos ${ }^{129}$.

\subsection{El argumento de la pluralidad cultural}

En otro artículo de The Guardian, el periodista británico Jonathan Freedland expone claramente cuál es el punto básico desde un enfoque antropocentrista:

Los musulmanes, los judíos y todos aquellos que valoran una sociedad plural necesitan tener la confianza para argumentar que sí, el bienestar animal importa, pero también la inclusión y la libertad religiosa-. No queremos que los animales sufran, pero tampoco queremos infligir el dolor del ostracismo y la exclusión a las minorías. Somos juzgados por cómo tratamos a los animales pero también por cómo tratamos a las personas, especialmente aquellas que son diferentes del resto. ${ }^{130}$

Así es, las sociedades multiculturales se presentan como dispositivos abiertos a otras formas culturales fuera de la dominante. Los partidarios de este modelo reivindican, de diversas formas, el reconocimiento e integración de las costumbres y ritos de los grupos minoritarios. Según Iris Marion Young, «el pluralismo democrático radical reconoce y afirma la importancia pública y política de las diferencias sociales como medio para garantizar la participación y la inclusión» ${ }^{131}$. Para Will Kymlicka, el estado multicultural repudia «la idea tradicional de que el Estado pertenece a un único grupo nacional [y] reconoce la injusticia histórica cometida en contra de las minorías [...] a través de la asimilación y exclusión» ${ }^{132}$. Se trata, por tanto, de asimilar o incluir a las culturas minoritarias. Ahora bien, estas políticas no están faltas de conflicto social. En primer lugar porque los grupos dominantes van a despreciar o estigmatizar a los minoritarios. $\mathrm{Y}$, en segundo término, porque las prácticas culturales de estos últimos grupos pueden vulnerar o contravenir valores aceptados por la mayoría de la sociedad. He aquí la necesidad de ponderar estos conflictos.

En un contexto internacional se evita la idea de una cultura hegemónica o imperialista. En la actualidad el imperialismo ha tomado diferentes formas de eliminar la diversidad cultural. La globalización económica capitalista y de hiperconsumo ha devorado buena parte del globo terráqueo. Las costumbres y los rituales tradicionales desaparecen a favor de una sociedad más homogénea, donde las tradiciones pierden terreno. Las sociedades occidentales demandan el cambio, el consumo de experiencias rápidas y transitorias, así es como la cultura va perdiendo narratividad y la comunidad se atomiza desligando los lazos propios de una cultura tradicional ${ }^{133}$. Por todo ello, desde un discurso antropocéntrico de los derechos humanos se podría aseverar que el respeto a los rituales religiosos que no afecten a los derechos fundamentales de los individuos (humanos) deben ser respetados e incluidos como parte de una sociedad plural, pues otros valores morales o jurídicos como el bienestar animal deben estar en un segundo grado.

Contra este enfoque se puede objetar que se da más valor a un rito prescindible y no obligatorio (como ya se ha expuesto) que al valor de la vida y la evitación del sufrimiento innecesario de un ser sintiente, es decir, que posee las mismas o similares capacidades de sentir dolor que los humanos. La igualdad y no discriminación puede verse realizada

${ }^{127}$ COHN-SHERBOK, D., Judaísmo, 84.

${ }^{128}$ EHRLICH, C.S., Entender el judaísmo (Barcelona 2006), 63.

${ }^{129}$ SCHAWARTZ, R. H., Vegetarianism: Essential for Jewish Renewal, en The Times of Israel, 26 de noviembre de 2017. Página Web: https://blogs.timesofisrael.com/vegetarianism-essential-for-jewish-renewal/ [Última consulta: 5 de diciembre de 2020].

${ }^{130}$ Traducción propia de FREEDLAN, J., Halal meat: animals shouldn't, but we mustn't ostracise minorities, en The Guardian, 9 de mayo de 2014. Página Web: https://www.theguardian.com/commentisfree/2014/may/09/halal-meat-animals-minorites-society [Última consulta: 5 de diciembre de 2020].

${ }^{131}$ Traducción propia de YOUNG, I. M., Justice and the Politics of Difference (Princenton N.J. 2011) 168.

132 KYMLICKA, W., Las odiseas culturales (Barcelona 2009) 79-80.

${ }^{133}$ HAN, B., La sociedad del cansancio (Barcelona 2019) 101.

120 Derecho Animal. Forum of Animal Law Studies, vol. 12/2 
sin tener que implicar los intereses básicos de los animales no humanos. Ciertamente, las sociedades tienen que estar abiertas al cambio y a la integración de las minorías, siendo positivo preservar parte de la cultura considerada tradicional. La justicia versa sobre la corrección de las desigualdades, pero ello no puede conllevar cometer otros actos injustos. Considerando moralmente a los animales, incrementar una política igualitaria no puede ser a costa de «sacrificar el bienestar de los mismos más vulnerables de los grupos. La igualdad no requiere nivelar la conducta moral a lo bajo: debemos subir el nivel en su lugar» ${ }^{134} \mathrm{y}$ demandar que el respeto a los demás animales sea un valor común. Valor que puede apoyarse, además, en la lectura de los textos sagrados de ambas religiones, si realmente se toman en serio los intereses de los animales.

\subsection{Conclusiones}

Un enfoque antropocéntrico fuerte sostendría que la libertad religiosa y de culto no puede ceder ante el bienestar animal. Si bien el judaísmo y el islam no se posicionan en contra de un estilo de vida vegetariano o vegano, las sagradas escrituras tampoco prohíben el consumo de carne mediante los ritos señalados. Estos rituales son seña de identidad de ambas religiones y abolirlas conllevaría un ataque a los valores de estos credos y, asimismo, entrarían en conflicto con ciertas posturas multiculturalistas e interculturalistas.

Los partidarios del bienestarismo podrán sostener conclusiones diferentes dependiendo de su enfoque concreto. Uno que se base en un antropocentrismo fuerte, donde los derechos y libertades de los seres humanos se situarán en por encima del valor que defiende reducir el máximo sufrimiento a los animales de consumo. En esta línea, sería criticable la postura tomada en diciembre de 2020 por el Tribunal de Justicia de la Unión Europea, pues el valor del bienestar animal no podría ir en detrimento de un derecho fundamental de la Carta, como es la libertad religiosa ${ }^{135}$. De otro lado, el segundo enfoque, relativo al antropocéntrismo débil, ponderaría cada caso según los intereses y valores en juego. Dentro de este grupo podrá sostenerse la misma conclusión que la anterior o bien reclamar que el bienestar animal está por encima de cualquier ritual religioso. Con mayor razón si una parte de esos grupos religiosos aprueban que la matanza puede realizarse sin que el animal esté consciente.

Sin embargo, la cuestión moral es también evidente y extensiva a las personas de otras religiones, ateas o aconfesionales. Así es, si no es necesario alimentarse de animales para llevar una vida saludable y una alimentación adecuada, ¿no sería incorrecto moralmente quitar la vida y hacer sufrir a animales solo para satisfacer ciertos gustos culinarios o culturales? Si consideramos moralmente en serio (con independencia del grado) a los animales, así como sus intereses de seguir con vida y no sufrir, hay básicamente dos opciones: a) consumir carne animal y seguir favoreciendo un sistema injusto según esta consideración, lo cual conlleva cierta disociación respecto a la moral y los actos; o b) llevar un estilo de vida respetuoso con esos intereses y dejar de aprovecharse de animales cuyo valor vital básico es similar al nuestro.

La postura que propugna los derechos de los animales sería nítida. A pesar del conflicto de intereses, ningún acto de culto puede justificarse en detrimento del derecho a la vida y a la prohibición de ser torturado $u$ objeto de tratos denigrantes. No sería razonable reconocer unos derechos basados en el sufrimiento de otros miembros de la comunidad moral. Además, tanto desde un punto de vista moral como social, sería relevante evidenciar la no necesidad de consumir animales según los textos sagrados. Es más, la compasión y evitar el dolor ajeno son valores identitarios de ambas religiones. Como se ha expuesto, el vegetarianismo era el estado original antes de las concesiones que Dios realizó tras el Diluvio Universal.

\section{Los animales y los pueblos indígenas}

Hablar de pueblos indígenas es hacer referencia a más de 370 millones de personas que viven en 90 países diferentes ${ }^{136}$. Es decir, múltiples idiomas, una enorme diversidad cultural y una pluralidad de circunstancias concretas. Basta hojear el texto de Indigenous Peoples' Food System: the many dimensions of culture, diversity and environment for nutrition and health ${ }^{137}$ para darse cuenta de las notables diferencias que existen entre una comunidad y otra a la hora de obtener recursos y alimentos.

En primer lugar, cabe concretar qué se entiende por pueblos indígenas. Pues bien, la Declaración de las Naciones Unidas sobre los Derechos Indígenas no contempla una definición del término indígena, aunque en su artículo 33 se establece el derecho a determinar su propia identidad y comunidad de acuerdo con sus costumbres y tradiciones ${ }^{138}$. Su

\footnotetext{
${ }^{134}$ Traducción propia de CASAL, P., Is Multiculturalism Bad for Animals? 22.

${ }^{135}$ En esta línea, el Abogado General Hogan, del Tribunal de Justicia, afirmó que el Estado belga no podía prohibir los rituales kosher y halal a la luz de la legislación europea, en concreto, en base a la excepción que se recoge respecto a la libertad religiosa del mencionado Reglamento $n^{\circ}$ 1099/2009. Léase en https://curia.europa.eu/jcms/upload/docs/application/pdf/2020-09/cp200104es.pdf [Última consulta: 6 de diciembre de 2020].

136 Programa para el Desarrollo de las Naciones Unidas (UNDP), Indigenous Peoples. Página web: https://www.undp.org/content/undp/en/home/2030-agenda-for-sustainable-development/peace/governance/indigenous-peoples.html [Última consulta: 8 de diciembre de 2020].

${ }^{137}$ KUHNLEIN, H. V.; ERASMUS, B.; y SPIGELSKI, B. E., Indigenous Peoples' Food System: the many dimensions of culture, diversity and environment for nutrition and health (Roma 2009), en http://www.fao.org/3/i0370e/i0370e.pdf [Última consulta: 8 de diciembre de 2020].

${ }^{138}$ Resolución aprobada por la Asamblea General el 13 de septiembre de 2007. Declaración de las Naciones Unidas sobre los derechos de los pueblos indígenas, en
} 
dificultad se basa en la multitud de culturas indígenas, lo cual hace ardua la tarea. En términos generales, se tratan de comunidades que históricamente han ocupado un territorio específico, cuya cultura es distintiva y se reconocen como tal $^{139}$. También conocidos como pueblos originarios, por mantener una cultura que ha pervivido durante siglos.

Es importante destacar, como así ha hecho la Food and Agriculture Organization of the United Nations (FAO), que los pueblos indígenas contribuyen con un desarrollo sostenible del planeta, conservan y favorecen los entornos naturales y ayudan a reconsiderar un sistema alimentario más sostenible basado en cereales, semillas y tubérculos ${ }^{140}$.

Se pueden hallar multitud de ejemplos de este estilo de vida sostenible. Así, los mayas tienen «maneras de ahuyentar, de cazar, de atraer a los animales silvestres que han sido practicadas durante siglos» ${ }^{141}$, $\mathrm{u}$ otras tribus, como los mískitas, han vivido del agua y los animales que habiten en ese ecosistema ${ }^{142}$. De hecho, se afirma desde la antropología que la disponibilidad de animales domesticados «desempeñó un papel importante en la prohibición del canibalismo y en el desarrollo de la religión de amor y misericordia en los estados e imperios del Viejo Mundo»» ${ }^{143}$.

Pero toda muerte animal por parte de los pueblos indígenas no obedece a motivos de supervivencia, también se da muerte a los animales como sacrificio a los dioses o a la Naturaleza. Ciertamente,

El equilibrio es el eje ordenador del buen vivir y sólo es posible lograrlo mediante la reciprocidad. Por eso los humanos conciben sagrada a la naturaleza, la reverencian y le piden que sea generosa con ellas. Las ofrendas y sacrificios son destinados a solicitar y a agradecer la fertilidad y la fecundidad que provee la Madre Tierra. ${ }^{144}$

Así pues, se puede hallar diferentes motivaciones o justificaciones al trato hacia los animales no humanos en un contexto de los pueblos indígenas. De tal modo que se analizarán diferentes argumentos. Dado el conflicto de intereses en juego, se realizarán una serie de reflexiones que, con mayor o menor acierto en su desarrollo, darán lugar a razonadas objeciones.

\subsection{El argumento de la diversidad cultural}

En un mundo globalizado y hegemonizador de la cultura de consumo, las comunidades indígenas poseen un valor material y simbólico muy importante respecto a la diversidad cultural.

En primer lugar, el Comité de Derechos Humanos ha reconocido a los pueblos indígenas como minorías a efectos del artículo 27 del Pacto Internacional de Derechos Civiles y Políticos ${ }^{145}$. No obstante, los pueblos indígenas ostentan en la comunidad internacional una protección mayor respecto a otras minorías nacionales. La mencionada Declaración sobre los Derechos de los Pueblos Indígenas es un buen ejemplo de ello. En particular, se reconoce el derecho de autodeterminación (artículos 3 y 4), se establece el derecho a la salud sin discriminación alguna (art. 21), así como mantener sus prácticas de salud, incluida la conservación de sus plantas medicinales, animales y minerales de interés vital (art. 24), y el derecho a mantener y fortalecer su relación con los recursos que tradicionalmente han poseído y ocupado (art. 25). Además, el Convenio número 169 de la Organización Internacional del Trabajo (OIT) incide en la importancia de estos pueblos para la diversidad cultural y en el derecho a la salud de los mismos.

De suerte que «Tratándose de pueblos indígenas, puede decirse que los principios más valiosos para ellos son los de multiculturalidad y derechos consiguientes a la propia cultura, el individual colectivo» ${ }^{146}$.

Numerosos defensores de los derechos humanos y de los derechos de los pueblos indígenas entienden que esta autonomía cultural y gubernativa, este estilo de vida en armonía con el ecosistema y la biodiversidad justifica su relación con los animales, aunque se den muerte o se sacrifiquen.

Para la objeción del argumento de la pluralidad cultural podría remitirse a lo expuesto en apartados anteriores. Remarcar, por ende, que la mera diversidad no es una buena razón ética por sí misma; de modo que el pluralismo cultural no puede ser un argumento válido si las prácticas culturales suponen una vulneración de los derechos o intereses de otros individuos de la comunidad; y, por último, no se trata de no valorar la diversidad cultural, la cual enriquece nuestro conocimiento y libertad, sino establecer unos límites mínimos a la aceptación de cualquier tipo de cultura. La diversidad cultural no desemboca en una apertura incondicional.

\subsection{El argumento de la necesidad: el derecho a la salud}

\footnotetext{
https://www.un.org/development/desa/indigenouspeoples/wp-content/uploads/sites/19/2018/11/UNDRIP_S_web.pdf

[Última consulta: 8 de diciembre de 2020].

139 Traducción propia de FAO, Pueblos indígenas. Página Web: http://www.fao.org/indigenous-peoples/es/ [Última consulta: 8 de diciembre de 2020].

${ }^{140}$ FAO, 6 ways indigenous peoples are helping the world achieve \#ZeroHunger, 9 de agosto de 2017, http://www.fao.org/zhc/detailevents/en/c/1028010/ [Última consulta: 8 de diciembre de 2020].

${ }^{141}$ Fondo para el desarrollo de los pueblos indígenas de América Latina y el Caribe. Modelo de vida de pueblos indígenas : maya, quechua, aymara, guaraní, mapuche, miskito y kuna (La Paz 2010) 72.

142 Idem, 99.

${ }^{143}$ HARRIS, M., Caníbales y reyes (Madrid 2007) 162.

${ }^{144}$ Fondo para el desarrollo de los pueblos indígenas de América Latina y el Caribe. Modelo de vida de pueblos indígenas : maya, quechua, aymara, guaraní, mapuche, miskito y kuna, 42.

${ }_{145}$ Véase en https://www.ohchr.org/SP/ProfessionalInterest/Pages/CCPR.aspx [Última consulta: 8 de diciembre de 2020].

146 JIMÉNEZ BARLETT, L., Diversidad cultural y pueblos indígenas (Bilbao 2009) 84.

122 Derecho Animal. Forum of Animal Law Studies, vol. 12/2
} 
Como se ha comprobado, la protección a la salud de los pueblos indígenas es reconocida por la comunidad internacional. Sin ir más lejos, conforme al artículo 24 de la Declaración Universal de Derechos Humanos, obtener una alimentación adecuada forma parte del derecho a la salud. Muchas comunidades han adaptado su alimentación a los recursos existentes en sus asentamientos ${ }^{147}$.

En este sentido, algunos defensores de los derechos humanos entienden que la caza debería formar parte de los derechos humanos para los pueblos indígenas si se entiende que esta práctica es un elemento identitario cultural y necesario para la subsistencia. Pues proteger a los animales ante la necesidad de estas comunidades «aparentemente concede mayor importancia a la vida silvestre que a la vida humana ${ }^{148}$. Incluso en los pueblos indígenas que tienen cierto contacto con sociedades occidentales, se remarca la importancia de la alimentación tradicional. Ejemplo de ello son las comunidades de los inuits:

Este cambio de una dieta basada en la subsistencia que consiste principalmente en alimentos del país (principalmente pescado, caribú, focas, ballenas, muskox y aves) a una dieta alta en alimentos comprados en las tiendas (menor valor nutricional, sin relevancia cultural y alto en conservantes) se ha identificado como una cuestión clave para la seguridad alimentaria en términos de la capacidad de acceder a alimentos nutricionalmente adecuados y culturalmente aceptables. ${ }^{149}$

Debido a todo esto, desde un punto de vista antropocéntrico, no es permisible que se restrinjan estas actividades de caza cuando tengan por objeto procurarse una adecuada alimentación. Aunque en la práctica este punto es conflictivo, pues existen numerosos casos en que las autoridades gubernamentales prohíben la caza de ciertas especies. He aquí cuando el argumento de la necesidad se mezcla con el argumento político. La complejidad del asunto no es objeto del presente trabajo, pero es necesario destacar varios casos para aproximarse a esta cuestión.

En Botsuana se prohibió la caza en todo el territorio, «incluso a los bosquimanos que dependen de ella para alimentar a sus familias; sin embargo existe una excepción para los cazadores que compiten por trofeos que pagan hasta 8.000 dólares por cazar jirafas y cebra» ${ }^{150}$. En Bolivia se prohibió el uso «de fauna silvestre "para el consumo alimenticio y medicinal en todo el territorio nacional". La medida, según los demandantes [los pueblos indígenas], atenta contra su medio de vida y cultura ${ }^{151}$, pero se permite el consumo de animales criados en industrias. Del mismo modo, indígenas de Japón reclaman su derecho a la pesca mientras que el gobierno niega que existan en la actualidad tribus indígenas en su territorio ${ }^{152}$. En otras partes del mundo, como en Camerún, las leyes anti-caza furtiva provoca que los indígenas cazadores sean arrestados ${ }^{153}$. Estos ejemplos muestran que las razones para prohibir o permitir la caza a los derechos no siempre encuentra una razón ética, sino que pasa por razones políticas o económicas.

La objeción a lo mencionado versa sobre la posibilidad de llevar una vida vegetariana siempre que no haya en esos contextos una necesidad nutricional de consumir carne. Pues tanto los huevos como la leche facilitan la ingesta de macronutrientes básicos.

Cuestión aparte de los intereses políticos y económicos, otra objeción que puede sostenerse, parafraseando a Marvis Harris ${ }^{154}$, es que el hecho de que la dominación sobre los animales haya desempeñado y siga desempeñando un papel destacado en los asuntos humanos no significa que deban seguir haciéndolo en cualquier futuro. Por primera vez en la historia, las alternativas a esta dominación están a nuestro alcance. Si no somo capaces de utilizarlas, no será un fracaso de la nuestra naturaleza, sino de nuestra inteligencia y voluntad. Se trata de acomodar, por consiguiente, las diferentes realidades culturales a los derechos básicos de los seres considerados moralmente relevantes. No por intentar eliminar la dominación que ejerce un grupo de la comunidad sobre otro supone repudiar una cultura determinada o la identidad de un grupo en concreto. La cultura debe intentar emanciparse de las posiciones de dominación y explotación,

\footnotetext{
${ }^{147}$ La microbiota intestinal del ser humano se puede adaptar a las condiciones alimenticias del entorno, facilitando la absorción de los nutrientes correspondientes. Aun así, muchas condiciones externas no son idóneas para obtener una alimentación saludable.

148 BENNETM G., Hunting must be regarded as a human right for indigenous and tribal peoples, en The Guardian, 16 de diciembre de 2020. Página Web: https://www.theguardian.com/global-development-professionals-network/2016/dec/16/respect-human-righthunt-indigenous-tribes [Última consulta: 8 de diciembre de 2020].

${ }^{149}$ HOOVER, C.; OSTERTAG, S.; HORNBY, C.; PARKER, C.; HANSEN-CRAIK, K.; LOSETO, L.; y PEARCE, T., The Continued Importance of Hunting for Future Inuit Food Security, en The Solutions Journal, julio 2016. Página Web: https://www.thesolutionsjournal.com/article/continued-importance-hunting-future-inuit-food-security/ [Última consulta: 8 de diciembre de 2020].

${ }^{150}$ SURVIVAL INTERNATIONAL, Botsuana prohíbe la caza de subsistencia de los bosquimanos pero permite la caza de trofeos para turistas de élite, 31 marzo de 2014. Página Web: https://www.survival.es/noticias/10115 [Última consulta: 8 de diciembre de 2020].

${ }^{151}$ LEYTÓN ARNEZ, D., Indígenas observan norma que prohíbe uso de fauna silvestre para consumo alimenticio y medicina, en La Región, 28 de abril de 2020. Página Web: https:/www.laregion.bo/indigenas-observan-norma-que-prohibe-uso-de-fauna-silvestrepara-consumo-alimenticio-y-medicinal/ [Última consulta: 8 de diciembre de 2020].

${ }^{152}$ LA VANGUARDIA, Indígenas ainu demandan a Japón para que se reconozcan sus derechos de pesca, 17 de agosto de 2020. Página Web: https://www.lavanguardia.com/vida/20200817/482875298313/indigenas-ainu-demandan-a-japon-para-que-sereconozcan-sus-derechos-de-pesca.html (Última consulta: 8 de diciembre de 2020).

153 EUROPA PRESS, El derecho a la caza de los pueblos indígenas, 24 de marzo de 2015. Página Web: https://www.europapress.es/sociedad/noticia-derecho-caza-pueblos-indigenas-20150324140457.html [Última consulta: 8 de diciembre de 2020].

${ }^{154}$ Argumento obtenido de HARRIS, M., Caníbales y reyes, 100-101. El autor solo hace referencia a la guerra y el sexismo, pues es bien sabido que no era un defensor del movimiento animalista. Es más, en el propio libro de esta cita se critica el vegetarianismo.
} 
cualquiera que sea su contexto.

\subsection{El argumento de la universalidad de la ética}

Es sabido que los derechos humanos tal como los conocemos surgieron en un determinado contexto tras las atrocidades del nacionalsocialismo en Alemania. Igualmente conocido son sus orígenes, que se encuentran en las dos grandes revoluciones del siglo XVIII. La pretensión de universalidad de sus valores arranca con el humanismo laico de la Ilustración ${ }^{155}$. Por eso, no son pocos los autores que señalan que los derechos humanos son un ideal de la individualidad humana propia de las concepciones liberales sobre lo que es el ser humano. Pues «si consideramos que el liberalismo es una cultura, entonces lo colocamos en el mismo lugar en cuanto a valía y dignidad entre las otras culturas» ${ }^{156}$, por ello, los postulados liberales acuden a la noción de que la libertad es la naturaleza propia del ser humano. A lo cual se objeta que es una postura de «raíz metafísica y no política de los derechos humanos» ${ }^{157}$. En base a la universalización de los valores de occidente surge la idea de colonialismo cultural. Esta crítica es extensiva a la teoría de los derechos de los animales. Añadir, por lo demás, que una postura ética, al versar sobre el estudio de la moral, tiende a ser universalizable, que no totalizadora. He aquí la problemática de acomodar una teoría ética a diferentes cosmovisiones y diversas costumbres de las comunidades humanas.

En este orden de cosas, Sue Donaldson y Will Kymlicka se preguntan si no es una forma de imperialismo moral imponer una ética animal de los derechos. Y es que «Al compararlo con la larga tradición de imperialismo occidental contra los pueblos indígenas, es difícil no verlo como otro ejemplo más en el que las sociedades occidentales se atribuyen el derecho a ejercer el poder contra sociedades indígenas sobre la base de que éstas son atrasadas, primitivas o incluso bárbaras» ${ }^{158}$. Por ello, destacan también los autores canadienses que muchos activistas por los derechos de los animales buscan cauces para eximir a las comunidades indígenas de las prohibiciones correspondientes.

Parece conveniente traer a colación el concepto de tolerancia positiva como «aprendizaje ético a partir de la alteridad» ${ }^{159}$ y que «se define sobre la base de una intolerancia, ya que si no se convertiría en una tolerancia ilimitada. Lo que ocurre es que la tolerancia positiva parte del hecho de la diferencia y no la prejuzga como necesariamente objetable» ${ }^{160}$. Un caso paradigmático donde los derechos humanos han tenido que conjugarse y acomodarse con los valores y la visión del mundo indígena es el caso del fuete o, concretamente, el caso Tyrer ${ }^{161}$. Ciertamente la práctica nos ofrece supuestos de difícil ponderación, lo que no conlleva que las exigencias morales más básicas pierdan su vigencia por cualquier motivo, pues, de lo contrario, «los principios morales no contendrían más que excepciones y, en consecuencia, podrían eliminarse por completo» ${ }^{162}$. Conforme a esta idea, Donaldson y Kymlicka afirman que

El trato a los animales es no solo un tema sobre el poder, el derecho o preferencias personales, sino una obligación ética de orden más alto. Esta creencia es compartida entre los defensores de los derechos de los animales y las perspectivas aborígenes, pero la estrategia de evitación obstruye este compromiso ético, lo que impide que se desafíen las visiones instrumentales y basadas en la propiedad. ${ }^{163}$

En efecto, si se mantiene una postura favorable a los derechos de los animales, la evitación de la controversia no asumiría la responsabilidad filosófica de analizar los conflictos de intereses, de no hacerse cargo de la actividad ética. Así pues, esta visión compartida de respeto al resto de seres vivos y a la naturaleza puede ser la piedra angular para un diálogo entre diferentes visiones, la base en la que sostener una comunicación intercultural.

\subsection{El argumento de la comunicación intercultural}

Una objeción práctica a la imposición de cánones morales puede ser la siguiente: «Si comenzamos a aplicar las leyes de protección animal más allá de nuestras fronteras prematuramente, corremos el riesgo de exacerbar sus aspectos problemáticos y déficits, que ya están surgiendo a nivel nacional» ${ }^{164}$. Por tanto, además de las razones que nos propone la ética comunicativa, se encuentra una razón de índole pragmática.

Así las cosas, parece oportuno abrazar una ética dialógica sobre la cuestión animal, donde se realice un intercambio de valores y pareceres, a través de una justicia que mantenga en equilibrio su aspecto procedimental y

${ }^{155}$ PECES BARBA, G.; DE ASÍS ROIG, R.; LIESA, C. R.; y LLAMAS GASCÓN, Curso de derechos fundamentales (Madrid 1991) 297.

${ }^{156}$ SERRANO SÁNCHEZ, J. A., Límites del multiculturalismo de Kymlicka para la defensa de los derechos de los pueblos indígenas, en En-claves del pensamiento, 2/3 (2008) 42.

${ }^{157}$ Idem., 45.

${ }^{158}$ DONALDSON, S., y KYMLICKA, W., Zoópolis, 87.

159 PÉREZ DE LA FUENTE, O., Pluralismo cultural y derecho de las minorías. Una aproximación iusfilosófica (Madrid 2005$) 413$.

${ }^{160}$ Idem., 412.

${ }^{161}$ Sentencia 5856/72 del Tribunal Europeo de Derechos Humanos, de 25 de abril de 1978, en

https://hudoc.echr.coe.int/eng\#\{\%22languageisocode\%22:[\%22SPA\%22],\%22appno\%22:[\%225856/72\%22],\%22documentcollecti onid2\%22:[\%22CHAMBER\%22],\%22itemid\%22:[\%22001-165149\%22]\} [Última consulta: 8 de diciembre de 2020].

162 WOLF, U., Ética de la relación entre humano y animales, 167.

${ }^{163}$ Traducción propia de KYMLICKA, W., y DONALDSON, S., Animal Rights and Aboriginal Rights, en Canadian Perspectives on Animal and the Law (2015) 186.

${ }^{164}$ Traducción propia de BLATTNER, C. E., Protecting animals within and across borders. Extraterritorial Jurisdiction and the Challenges of Globalization (Oxford 2019) 405.

124 Derecho Animal. Forum of Animal Law Studies, vol. 12/2 
sustantivo. La responsabilidad de los interlocutores en base a una ética de la compasión y la solidaridad es primordial, en tanto que «entender la relación intersubjetiva bajo el modelo de estructura responsiva es la condición de posibilidad de un discurso moral sobre mínimos [...]. He ahí una de las bases para poder hablar de ética global» ${ }^{165}$. Una ética mínima guiaría los comienzos de este diálogo, pues como hemos expuesto al inicio del trabajo, ninguna cultura es completa y la comunicación entre las culturas es enriquecedora. Esta ética de mínimos se centraría en normas que «tengan en cuenta los intereses de todos los afectados en pie de igualdad ${ }^{166}$ teniendo en cuenta las circunstancias fácticas para llegar al objetivo de la integración de una ética animal, evitando así consideraciones idealistas que, a pesar de las buenas intenciones, acaben por convertirse en «ética-ficción». El reto se basaría en diseñar estrategias que acomoden esta ética a los pueblos indígenas en compatibilidad «con la soberanía de las mismas y sus dinámicas políticas internas» ${ }^{167}$. Ahora bien, sería aconsejable que los defensores de los derechos humanos que se tomen en serio los derechos de los animales tuvieran presente que

ni la búsqueda de la igualdad, ni el deseo de preservar la diversidad justifican un derecho cultural a la crueldad. Más bien lo niegan: la preocupación por los más vulnerables y desfavorecidos, que motiva nuestro apoyo a las minorías, es un principio que prohíbe también el sacrificio de los más vulnerables dentro de las minorías. ${ }^{168}$

En otras palabras, el diálogo no se plantearía como un camino sin conflictos ni pretensiones de actos coherentes con esta ética animalista. No se trataría de acomodarse en el simple hecho del diálogo. Habría que favorecer las condiciones materiales para facilitar el cambio en las comunidades que no partan de una ética animal de los derechos. La base del intercambio de ideas es simple: la cultura es cambiante, no permanece pura, pues su esencia es la mezcla, el encuentro entre diferentes individuos es siempre posible y, a menudo, necesaria. En este caso, necesaria para aquellos que no tienen ni siquiera voz para defender sus intereses frente a los humanos. La ética es un elemento transformador, pero son los individuos y los grupos quienes tienen que considerarse participes de ese cambio.

\subsection{Conclusiones}

Desde un punto de vista antropocéntrico fuerte podría sostenerse que los pueblos indígenas deben ser objeto de fuertes políticas de protección de su cultura. Las culturas indígenas proporcionan una riqueza cultural necesaria para los valores que defienden tanto los multiculturalistas como los interculturalistas. Además, su relación con la naturaleza y los animales es sostenible. Su autonomía debe ser respetada y la imposición de una ética animal vendría a imponer un canon moral parcialmente ajeno a las cosmovisiones de estas comunidades.

Un enfoque antropocéntrico débil, como es el bienestarista, defendería las razones expuestas anteriormente. Tal vez cabría añadir que las relaciones con los animales deberían estar guiadas por los presupuestos de la necesidad (derecho a la alimentación) y del menor sufrimiento posible de los animales. Excluyendo de tal manera, las prácticas tradicionales de los grupos indígenas que no se ajusten a estos criterios.

Una posición animalista, basada en los derechos de los animales, se centraría en el conflicto de derechos e intereses de todos los seres considerados moralmente: humanos y no humanos. La posibilidad de encontrar todos los nutrientes básicos para la vida humana limita las condiciones de justicia. El reproche moral ante un hecho injusto debe atenuarse o limitarse dependiendo de las circunstancias. Lo cual no conlleva que el hecho deje de ser incorrecto en relación con el valor de los no humanos, pues se estaría ante la falacia naturalista ${ }^{169}$. A saber: si algo es de tal manera, es lo correcto y lo deseable. Habría que diferenciar, de este modo, las circunstancias empíricas de las propuestas deontológicas. Si bien estas circunstancias pueden ayudar a entender las motivaciones de los agentes morales, tampoco conlleva que la ética animal de los derechos no pretenda ser universal, ya que sus principios deben ser una meta para todas las culturas, una guía para cualquier comunidad humana reflexione sobre su relación con el resto de animales. Esta ética debe verse reflejada en derechos, pero

Si pensamos que los derechos son metas hacia las que hay que correr, intentaremos salvar el mayor número de vidas. Si pensamos que los derechos son meras barreras o constricciones, como las vallas de un maratón que marcan la pista por donde se puede correr, dejaremos que el vagón siga su curso. No importa llegar a la meta, sólo respetar las barreras. ${ }^{170}$

Por eso, tanto la ética animal como los derechos deben ser una meta, porque lo importante es avanzar en la concienciación y la protección de los sujetos moralmente relevantes, cuya implementación debe venir dada por una normativa ejemplar. No se trata, pues, de imponer meras medidas restrictivas que puedan ser acatadas o sorteadas. La motivación de la conducta social es esencial en el respeto al otro, no basta con la mera imposición. De forma muy simple, no se deja de matar porque lo prohíba el código penal, sino porque la inmensa mayoría de la sociedad reconoce que es

\footnotetext{
${ }^{165}$ GÓNZALEZ R. ARNAIZ, G., Interculturalidad y convivencia. El “giro intercultural” de la filosofía (Madrid 2008$) 117$.

${ }^{166}$ CORTINA. A., Ética mínima, 309.

${ }^{167}$ MUÑOZ CUENCA, A., El conflicto entre los derechos culturales y los derechos de los animales no humanos: una propuesta de mediación, Revista Latinoamericana de Estudios Críticos Animales, 2/5 ( 2018) 235,

http://revistaleca.org/journal/index.php/RLECA/article/view/166 [Última consulta: 9 de diciembre de 2020].

${ }^{168}$ CASAL, P., Cultura y crueldad, 77-78.

169 De igual modo, los enfoques animalistas tampoco deberían caer en la falacia moralista.

${ }^{170}$ CASAL, P., Los derechos homínidos. Una defensa ecuménica, en Daimon. Revista Internacional de Filosofía. 73. (2018) 21.
} 
un acto inmoral. La ética animal debe ser una exigencia tanto interna como externa. Ahora bien, esta exigencia debe ser puesta en contexto. Desde un punto de vista político, en la actualidad es incoherente criticar a los pueblos indígenas que no respetan los intereses básicos de los animales cuando en occidente y oriente no paran de torturarles, consumirlos, dominarlos y explotarlos. Solo ante un escenario generalizado de una posición animalista aplicada podría darse el diálogo intercultural. Como ya se ha dicho, no es legítimo criticar a otras culturas por injusticias similares e incluso cuantitativa y cualitativamente menos graves a las que se cometen en nuestras sociedades. Signo que denota un fuerte etnocentrismo. Los actos contra los intereses de los animales son moralmente incorrectos, pero la necesidad de alimentarse adecuadamente de ciertos humanos (como parte de la comunidad animal) deben modular la exigencia política. Sin perjuicio de demandar un enfoque más respetuoso con estos. Esto es así porque se en muchas comunidades no es fácil conseguir un aporte de proteínas vegetales suficientes, por no mencionar las vitaminas A o B12 y una fuente alta de hierro u omega 3. Nutrientes necesarios para mantener una buena salud. Supuesto distinto son las matanzas de animales por cuestiones culturales o económicas, que poco o nada tienen que ver con la supervivencia. En estos casos, el análisis estaría más ajustado a los dos apartados anteriores de este trabajo. En definitiva, toda comunidad debería asumir que la explotación animal es en potencia una opción y no una necesidad inevitable. Si bien es verdad que esa inevitabilidad pasa por un cambio cultural y alimentario que, a su vez, conlleva la introducción de nuevos elementos en las culturas indígenas. Esta apertura vendría dada por el reconocimiento de los intereses básicos de los animales, que debe ser requerida por las propias comunidades y no meramente consentida, de modo que los propios miembros adopten una ética animal conforme a su propia cultura. Asumiendo todas las culturas una ética de responsabilidades fuertes y unas identidades débiles ${ }^{171}$. En esta línea, no se trata de imponer un canon o una suerte de imperialismo cultural, sino de un reconocimiento general a través de una ética dialógica y una ética de la alteridad, la solidaridad y la compasión. Una ética a la que toda comunidad humana podría aspirar mediante la riqueza que ofrece el pluralismo cultural.

\section{Conclusiones generales}

Tras el análisis de los tres casos de conflicto, más allá de las conclusiones particulares, se ha podido comprobar que hay varios argumentos constantes en el debate. Ahora bien, con matices distintos. La diversidad cultural, la libertad o la necesidad convergen en torno a la ética de forma diferente en los tres supuestos. Ello, en consecuencia, ha evidenciado una serie de choques entre algunos derechos humanos y los derechos de los animales. En este sentido, se ha puesto de relieve que la ética animal también es una cuestión transversal para el multiculturalismo e interculturalismo. Si se toman en serio los intereses básicos de los animales, las teorías que abordan el pluralismo cultural deberían modular sus postulados sobre esta cuestión.

De otro lado, la ética de la alteridad es crucial tanto para el estudio del fenómeno del pluralismo cultural como en los planteamientos animalistas. Los ejemplos expuestos en este trabajo no son otra cosa que una breve exploración aplicada sobre la otredad. En esta línea, se han abordado, bien de forma explícita o implícita, temas como el etnocentrismo y la universalización de una determina ética. Por ello, el texto analiza en primer lugar la tauromaquia para dar paso al examen de situaciones conflictivas en otras culturas. Intentando encontrar así una línea razonable en la exposición.

En definitiva, esta amplia fotografía de la cuestión animal ha pretendido mostrar las complicaciones que se derivan tanto del análisis aislado de los casos (pues no reflejan su trascendencia respecto a otros supuestos) como de un estudio generalizado (dado que su ámbito es tan amplio y complejo que dificulta un planteamiento carente de singularidades). Por eso, el objetivo de este texto era trazar una serie de reflexiones en relación con los argumentos que se pueden esgrimir y objetar a raíz de la conexión entre la ética animal y la diversidad cultural. Si los lectores han sido interpelados tanto por la idea principal como por los diferentes argumentos, se habrá cumplido con el modesto objetivo de este trabajo.

\section{BIBLIOGRAFÍA}

- ASERIN FARACHE, C., Las leyes dietéticas del judáismo. Una dieta para el alama, Aldaba. 36 (2013). DOI: https://doi.org/10.5944/aldaba.36.2012.20533.

- BAUMAN, Z., Vida líquida (Barcelona 2009).

- BLATTNER, C. E., Protecting animals within and across borders. Extraterritorial Jurisdiction and the Challenges of Globalization (Oxford 2019).

- BRANCA, P., Los musulmanes (Madrid 2004).

- CASAL, P., Is Multiculturalism Bad for Animals?, en The Journal of Political Philosophy, 11/1 (2003): 1-22. DOI: $10.1111 / 1467-9760.00164$

- CASAL, P., Cultura y crueldad». En Animales no humanos entre animales (Madrid 2012) 47-84.

- CASAL, P., Los derechos homínidos. Una defensa ecuménica, en Daimon. Revista Internacional de Filosofía. 73 (2018) 7-25.

- CASTRO, E., Ética, estética y política. Ensayos (y errores) de un metaindignado (Barcelona 2020).

- CODINA SEGOVIA, J. I., Pan y toros. Breve historia del pensamiento antitaurino español (Madrid 2018).

- COHN-SHERBOK, D., Judaísmo (Madrid 2001).

- COHN-SHERBOK, D., Breve enciclopedia del judaísmo (Madrid 2003).

${ }^{171}$ CRUZ, M., Hacerse cargo. Por una responsabilidad fuerte y unas identidades débiles (Barcelona 2015) 160-161. 
- CORÁN, Al-Maidah 5:4, en https://www.ahmadiyya-islam.org/es/coran/capitulos/5/

- CORTINA, A., y MARTÍNEZ NAVARRO, E., Ética (Madrid 2001).

- CORTINA, A., Ética mínima (Madrid 2020).

- CRUZ, M., Hacerse cargo. Por una responsabilidad fuerte y unas identidades débiles (Barcelona 2015).

- DAWKINS, R., El gen egoísta Extendido (Madrid 2017).

- DECKHA, M., Is Multicuturalism Good for Animals?, en Animals, Race, and Muticulturalism (London 2017), 61-93. DOI: https://doi.org/10.1007/978-3-319-66568-9_4

- DE SOUSA SANTOS, B., El milenio huérfano. Ensayos para una nueva cultura política (Madrid 2005).

- EHRLiCH, C. S., Entender el judaísmo (Barcelona 2006).

- FERNÁNDEZ TRESGUERRES, A., La corrida de toros como ceremonia angular: una interpretación materialista, en Revista de Estudios Taurinos, 12 (2000) 71-88, en https://idus.us.es/handle/11441/79522 [Última consulta: 20 de noviembre de 2020].

- Fondo para el desarrollo de los pueblos indígenas de América Latina y el Caribe. Modelo de vida de pueblos indígenas: maya, quechua, aymara, guaraní, mapuche, miskito y kuna. La Paz, Bolivia: Fondo indígena, 2010.

- FOUCUlT, M., Las palabras y las cosas (Ciudad de México 2010).

- FRANCIONE, G. L., The Abolition of Animal Exploitation, en Francione, G. L. y Garner, R., The Animal Rights Debate, Abolition or Regulation (Nueva York 2010) 1-102 .

- GÓMEZ GARCÍA, L., Diccionario de islam e islamismo (Madrid 2009).

- GÓMEZ MANRIQUE, A., Estudio de viabilidad de instalación de una planta de producción de vitamina B12 en España, Cuadernos del Tomás, 9 (2017): 107-139. https://dialnet.unirioja.es/descarga/articulo/6245306.pdf

- HAN, B., La sociedad del cansancio (Barcelona 2019).

- HARRIS, M., Caníbales y reyes (Madrid 2007).

- HARRIS, M., Vacas, cerdos, guerras y brujas (Madrid 2007).

- hOLZWARTH, H. W., Arte moderno (Colonia 2016).

- hoover, C., OStertag, S.; HORNBY, C.; PARKER, C.; HANSEN-CRAIK, K.; LOSETO, L.; y PEARCE, T., The Continued Importance of Hunting for Future Inuit Food Security, en The Solutions Journal, julio 2016. Página Web: https:/www.thesolutionsjournal.com/article/continued-importance-hunting-futureinuit-food-security/ [Última consulta: 8 de diciembre de 2020].

- KUHNLEIN, H. V.; ERASMUS, B.; y SPIGELSKI, B. E., Indigenous Peoples' Food System: the many dimensions of culture, diversity and environment for nutrition and health (Roma 2009), en http://www.fao.org/3/i0370e/i0370e.pdf [Última consulta: 8 de diciembre de 2020].

- KYMLICKA, W., Las odiseas multiculturales (Barcelona 2009).

- KYMLICKA, W., y DONALDSON, S., Animal Rights and Aboriginal Rights, en Canadian Perspectives on Animal and the Law. Irwin Law (2015) 159-186.

- $\quad$ LARA, F., y CAMPOS, O., Sufre, luego importa. Reflexiones éticas sobre los animales (Madrid 2015).

- MARINA, J.A., , La inteligencia fracasada. Teoría y práctica de la estupidez (Barcelona 2008).

- MILL, J. S., Sobre la libertad (Madrid 1970).

- MONAGHAN, J., y PETER, J., Social \& Cultural Anthopology. A Very Short Introduction (Oxford 2000).

- MONTURIOL, Y., Términos clave del islam (Córdoba 2006).

- MOSTERÍN, J., A favor de los toros (Pamplona 2010).

- MOSTERÍN, J., El triunfo de la compasión. Nuestra relación con los otros animales (Madrid 2015).

- MOSTERÍN, J., El islam. Historia del pensamiento (Madrid 2018).

- MUÑOZ CUENCA, A., El conflicto entre los derechos culturales y los derechos de los animales no humanos: una propuesta de mediación, en Revista Latinoamericana de Estudios Críticos Animales, 2/5 (2018) 220239. http://revistaleca.org/journal/index.php/RLECA/article/view/166

- PECES BARBA, G.; DE ASÍS ROIG, R.; LIESA, C. R.; y LlAMAS GASCÓN, Curso de derechos fundamentales (Madrid 1991).

- PULEO, A., Ecofeminismo para otro mundo posible (Madrid 2019).

- RAWLS, J., Teoría de la justicia (Madrid 1997).

- SAVATER, F., Tauroética (Madrid 2011).

- SERRANO SÁNCHEZ, J. A., Límites del multiculturalismo de Kymlicka para la defensa de los derechos de los pueblos indígenas, en En-claves del pensamiento, 2/3 (2008) 27-45.

- TURBÓN BORREGA, D., Evolución y adaptación del comportamiento», en Etología (Barcelona 2019).

- VALENCIA CANDALIJA, R., Sacrificio ritual y alimentación kosher: referencia a las novedades legislativas sobre la sechita en Bélgica, en Anuario de Derecho Eclesiástico del Estado de la Universidad de Sevilla, XXXV (2019) 377-414. https://www.boe.es/biblioteca_juridica/anuarios_derecho/abrir_pdf.php?id=ANUE-201910037700416_ANUARIO_DE_DERECHO_ECLESI\%C3\%81STICO_Sacrificio_ritual_y_alimentaci\%C3 $\%$ B3n_Kosher:_referencia_especial_a las_novedades_legislativas_sobre_la_Shechita_en_B\%C3\%A9

- VELASCO SESMA, A., La ética animal. ¿Una cuestión feminista? (Madrid 2019).

- VERICAT, M., Filosofía y toros. Un debate ético (Barcelona 2018). 
- VILLORO, L., Los retos de la sociedad por venir (México D.F. 2007).

- WOLF, U., Ética de la relación entre humanos y animales (Madrid 2014).

- WOLFF, F., , 50 razones para defender la corrida de toros (Córdoba 2019).

- YOUNG, I. M., Justice and the Politics of Difference. (Princenton 2011).

\section{ARTÍCULOS DE PRENSA ELECTRÓNICA}

- BENNET, G., Hunting must be regarded as a human right for indigenous and tribal peoples, en The Guardian, 16 de diciembre de 2020.

https://www.theguardian.com/global-development-professionals-network/2016/dec/16/respect-human-righthunt-indigenous-tribes

- CERILlO, A., La epidemia da la estocada a los toros, en La Vanguardia, 3 de junio https://www.lavanguardia.com/cultura/20200703/482055792657/la-epidemia-da-l

de 2020. banuelos-el-fundi.html a-estocada-toros-

- EL PLURAL, Encuesta: Casi la mitad de los españoles, a favor de prohibir los toros, 6 de mayo de 2020. https://www.elplural.com/sociedad/encuesta-mitad-espanoles-favor-prohibir-toro $\quad$ s_239267102

- $\quad$ EUROPA PRESS, El derecho a la caza de los pueblos indígenas, 24 de marzo de 2015. https://www.europapress.es/sociedad/noticia-derecho-caza-pueblos-indigenas-20 150324140457.html

- FREEDLAN, J., Halal meat: animals shouldn't, but we mustn't ostracise minorities, en The Guardian, 9 de mayo de 2014.

https://www.theguardian.com/commentisfree/2014/may/09/halal-meat-animals-m inorites-society

- GÓMEZ PIN, V., (entrevistado por Agencia EFE), Víctor Gómez Pin: "Sin el toreo perderíamos una referencia ética y estética”, en La Razón, 15 de mayo de 2012.

https://www.larazon.es/historico/6444-victor-gomez-pin-sin-el-toreo-perderiamos -una-referenciaetica-y-estetica-JLLA_RAZON_457940/

- INFOLIBRE, El 84\% de los jóvenes de 16 a 24 años se avergüenza de vivir en un país con toros, 21 de enero de 2016.

https://www.infolibre.es/noticias/politica/2016/01/21/el_los_jovenes_24_anos_esta_quot_poco_quot_quot_n ada_quot_orgulloso_vivir_pais_con_toros_43668_1012.html

- KOSC, W., Nine out of 10 EU citizens oppose animal slaughter without stunning, poll finds, en The Guardian, 9 de octubre de 2020.

https://www.theguardian.com/environment/2020/oct/09/nine-out-of-10-eu-citizen s-oppose-animalslaughter-without-stunning-poll-finds

- LA VANGUARDIA, El mayor sacrificio religioso de animales del mundo sigue adelante a pesar de las prohibiciones, 5 de diciembre de 2019. https://www.lavanguardia.com/vida/20200817/482875298313/indigenas-ainu-de mandan-a-japonpara-que-se-reconozcan-sus-derechos-de-pesca.html

- LA VANGUARDIA, Indígenas ainu demandan a Japón para que se reconozcan sus derechos de pesca, 17 de agosto de 2020.

https://www.lavanguardia.com/natural/20191205/472062751285/mayor-sacrificio -del-mundomatanza-animal-festival-gadhimai-nepal-india.html

- LIPHSHIZ, C., Belgian ban on kosher slaughter has Jews worried about what comes next», en Times of Israel, 4 de enero de 2019.

https://www.timesofisrael.com/belgian-ban-on-kosher-slaughter-has-jews-worrie d-about-whatcomes-next/

- MUNDOTORO, Fernando Savater: "Los toros deben ser respetados y protegidos por el Gobierno, en AS, 25 de febrero de 2010. https://as.com/diarioas/2010/02/25/toros/1267052401_850215.html

- MUÑOZ GÓMEZ, F., El artista que dejó morir de hambre a un perro en en una galería de arte, en ABC blogs, 7 de agosto de 2015 .

https://abcblogs.abc.es/archivos-desclasificados/2015/08/07/matar-hambre-perro/

- PÉREZ BENAVENTE, R., Bienestar animal en las granjas: no sólo es una cuestión ética, sino también económica», en Público, 4 de septiembre de 2019. https://www.publico.es/sociedad/granjas-animales.html

- PÉREZ DE LA FUENTE, O., Pluralismo cultural y derecho de las minorías. Una aproximación iusfilosófica (Madrid 2005).

- REJÓN, R., Los toros pierden medio millón de asistentes en los últimos cuatro años, en El Diario, 1 de octubre de 2019. Según la encuesta de hábitos y prácticas culturales del Ministerio de Cultura. https://www.eldiario.es/sociedad/toros-pierden-medio-millon-asistentes_1_1335222.html

- SCHAWARTZ, R. H., Vegetarianism: Essential for Jewish Renewal, en The Times of Israel, 26 de noviembre de 2017.

https://blogs.timesofisrael.com/vegetarianism-essential-for-jewish-renewal/ 
- ZRAICK, K., Is Stunning an Animal Before Slaughter More Humane? Some Religious Leaders Say No, en The New York Times, 9 de enero de 2019. https://www.nytimes.com/2019/01/09/world/europe/halal-kosher-humane-slaughter.html

\section{OTRAS FUENTES}

- BUENO, G., Sobre los toros, en Teselas, 36, 20 de abril de 2010, en http://fgbueno.es/med/tes/t036.htm

- FAO, 6 ways indigenous peoples are helping the world achieve \#ZeroHunger, 9 de agosto de 2017, en http://www.fao.org/zhc/detail-events/en/c/1028010/

- FAO, Pueblos indígenas, en http://www.fao.org/indigenous-peoples/es/

- GARAEV, P., Ban on ritual slaughter causes Belgium's Jews to import meat form i24news, de 2 de junio de 2019 , en https://www.i24news.tv/en/news/international/europe/192316-190102-ban-on-rit causes-belgium-s-jews-to-import-meat-from-hungary

Hungary, ual-slaughter-

- LEYTÓN ARNEZ, D., Indígenas observan norma que prohíbe uso de fauna silvestre para consumo alimenticio y medicina», en La Región, 28 de abril de 2020, en https://www.laregion.bo/indigenas-observan-norma-que-prohibe-uso-de-fauna-sil vestre-paraconsumo-alimenticio-y-medicinal/

- LUVAVITCH, J., Vegetarianismo en la perspectiva judía,en Tu guía del judaísmo, en https://www.tora.org.ar/vegetarianismo-en-la-perspectiva-judia/

- Programa para el Desarrollo de las Naciones Unidas (UNDP), Indigenous Peoples, en https://www.undp.org/content/undp/en/home/2030-agenda-for-sustainabledevelopment/peace/governance/indigenous-peoples.html

- SURVIVAL INTERNATIONAL, Botsuana prohíbe la caza de subsistencia de los bosquimanos pero permite la caza de trofeos para turistas de élite, 31 marzo de 2014, en https://www.survival.es/noticias/10115

- VEGAN SOCIETY, Definition of veganism, en https://www.vegansociety.com/go-vegan/definition-veganism

\section{FUENTES JURISPRUDENCIALES}

- Sentencia 5856/72 del Tribunal Europeo de Derechos Humanos, de 25 de abril de 1978, en https://hudoc.echr.coe.int/eng\# \{\%22languageisocode\%22:[\%22SPA\%22],\%22appno\%22:[\%225856/72\%22 ],\%22documentcollectionid2\%22:[\%22CHAMBER\%22] ,\%22itemid\%22:[\%22001-165149\%22]\}

- Sentencia del Tribunal de Justicia de la Unión Europea, de 19 de mayo de 2018, en http://curia.europa.eu/juris/document/document.jsf;jsessionid=1FC143A8A584D4DB7C0DE48F7D7D5FF2 ?text $=\&$ docid $=202301 \&$ pageIndex $=0 \&$ doclang $=E S \&$ mode $=1$ st\&dir $=\&$ occ $=$ first \&part $=1 \&$ cid $=15978186$

- Sentencia de 17 de diciembre de 2020, sobre asunto C-336/19 del Tribunal de Justicia de la Unión Europeo, en http://curia.europa.eu/juris/document/document.jsf;jsessionid=149CBC8612FC08E51F3261F5C4E8F973?te $\mathrm{xt}=\&$ docid $=235717$ pageIndex $=0 \&$ doclang $=\mathrm{ES} \&$ mode $=$ req\&dir $=\& o c c=$ first $\&$ part $=1 \& \operatorname{cid}=23538518$ 